\title{
Some Macro Foundations for Micro Theory
}

THIs paper examines the course of inflation in the United States since the turn of the century as a means of throwing light on several major controversies in current research on inflation. The paper does not attempt to build a better econometric model of the inflation process. Rather, it is an exercise in analytical history that suggests certain conclusions about wage and price behavior at odds with the recent accelerationist variants of inflation theory.

The paper is principally concerned with the economy's aggregate supply curve. The discussion considers the influence of monetary and other elements of demand management policy on the shape of that curve through their effect on expectations. But it does not deal with the determinants of aggregate demand nor does it enter the controversy about the role of money versus other factors determining demand. It takes the course of aggregate demand as given and concentrates upon the response of inflation to it.

Throughout most of the paper the basic unit of observation is a business-cycle expansion or contraction. Units of data are measured not over quarterly or annual intervals but are expressed as average levels or rates of change during each expansion or contraction. With eighty years of business-cycle history and a total of twenty-seven expansions and contractions-not counting the wartime cycles-there are sufficient observations to conduct the quantitative analysis in this way.

I am grateful to Robert J. Gordon, who provided extensive comments, and to members of the Brookings panel for their help during the preparation of this paper. Research assistance was ably provided by Thomas C. Hier and Stephen L. Garbacz. 
This approach is a complement to, not a substitute for, the use of annual and quarterly econometric equations as a device to test hypotheses about the behavior of inflation. Grouping the data into cycle expansions and contractions has some disadvantages. It is obviously not a good way to ferret out lag structures. (As a consequence, on occasion I use monthly series to examine cyclical patterns of price acceleration and deceleration.) And, because this procedure averages annual data within each cyclical phase, it reduces the variance of the data and so loses some information.

The cyclical approach has some important advantages, however. The ratio of measurement noise to true signal is likely to be much smaller when comparing variable averages in expansion to those in contraction than when comparing one year's data to the next, especially in a study that must rely upon data from cycles as far back as 1900 . Moreover, breaking the eighty-year period into a relatively small number of business cycles lends itself to an examination of particular questions in ways that sometimes give more insight than do regression equations. For example, is the rise in employment typically kept going during cycle expansions by an acceleration of inflation a la Friedman-Phelps?

I begin by examining the responsiveness of inflation to changes in aggregate demand in the expansions and contractions of peacetime business cycles from 1900 to the mid-1960s. Particular emphasis is placed on determining whether that response altered between the prewar and postwar periods. Differences in behavior between prices and wages are examined, as are differences among various measures of prices. I extend the analysis to look at the role of the level of demand (Phillips curve) and the historical presence or absence of accelerationist tendencies during cycle phases over the same period. The behavior of inflation during the two wartime cycles (which turns out to have been quite different from behavior at other times) is then investigated, and the period from 1966 to the present is separately examined. In each section some implications of the findings for the competing theories of the inflationary process are suggested, and these are summarized. ${ }^{1}$

1. Robert Gordon, in a series of recent papers, has subjected the long-term behavior of inflation to econometric analysis. Some of the major conclusions in this paper confirm Gordon's findings; for instance, Gordon notes in his comments on this paper that the rate of change in output, employment, and nominal GNP plays a large part in determining the course of inflation. On the other hand, some of the conclusions of this paper differ from those of Gordon, and these are indicated. See Robert J. Gordon, "Why Stopping Inflation May be Costly: Evidence from Four- 
This paper was originally conceived as the first step in an analysis of a presumed postwar decrease in the cyclical sensitivity of price and wage behavior to changes in aggregate demand, a phenomenon apparently well documented by Cagan and Sachs. ${ }^{2}$ The paper begins, therefore, with an attempt to measure the cyclical responsiveness of inflation to movements in aggregate demand. But the nature of the measurement itself depends in part upon the theoretical structure that one believes best describes the cyclical inflationary process. One can relate the level, rate of change, or acceleration and deceleration of prices to the level, rate of change, or acceleration and deceleration of aggregate demand variables. The alternative sets of relations can roughly be grouped according to doctrinal views about the process of inflation.

While the best part of a library could be stocked with material bearing on the subject, the competing approaches to macro inflation theory in the past thirty years can be condensed into the following four basic approaches to modeling the inflation process.

The early Keynesian view and "speed limit" approaches. The level of prices is a function of the level of actual output (or employment) relative to potential output (or labor force), subject to a special constraint of wages that are sticky downward. The rate of change in price depends upon the rate of change in employment or output.

This Keynesian model of the aggregate supply curve is based on the presumed need for a rise in prices relative to unchanged wages, as employers move down their labor demand curves, and from the increase in wages that would begin to occur in the region of full employment. It is not necessary to rely upon the dubious assumption that real wages systematically move inversely with output, however, to show that the price level may move with the level of output. As is discussed below, wage in-

teen Historical Episodes," Conference Paper 108 (National Bureau of Economic Research, 198 $\rightarrow$ "A Consistent Characterization of a Near-Century of Price Behavior," American Economic Review, vol. 70 (May 1980, Papers and Proceedings, 1979), pp. 243-49; "Price Inertia and Policy Ineffectiveness in the United States 1890-1980" (Northwestern University, Department of Economics, September 1981 ); and "Output Fluctuation and Gradual Price Adjustment," Journal of Economic Literature, vol. 19 (June 1981), pp. 493-530.

2. Phillip Cagan, "Changes in the Recession Behavior of Wholesale Prices in the 1920's and Post-World War II," Explorations in Economic Research, vol. 2 (Winter 1975), pp. 54-104; Jeffrey Sachs, "The Changing Cyclical Behavior of Wages and Prices: 1890-1976," American Economic Review, vol. 70 (March 1980), pp. 78-90. 
creases may occur in expanding firms as a means of channeling a flow of job applicants from the Keynesian unemployed to those firms. The size of the increase needed is a function of the magnitude of the expansion. The rate of inflation thus depends upon the rate of change in employment and output.

The Phillips curve. In Arthur Okun's phrase, the Phillips curve slipped a derivative on the earlier formulation. The rate of change of prices is expressed as a function of the level of unemployment or of the gap between actual and potential output. The cost of improving the economy's utilization rate is a one-time increase in the rate of inflation.

The Phelps-Friedman adaptive accelerationist view. In the next phase the derivative slips still another notch. The rate of change of inflation is now a function of the gap or the unemployment rate. The equilibrium or "natural" rates of unemployment and output are given by the intersection of labor demand and supply curves. Market-clearing forces will move wages and prices to establish that equilibrium. The real wage that enters the labor supply curve is based, however, on an expected rate of general inflation in prices, wages, or both that adapts promptly but not instantaneously to actual inflation experience. As a consequence, whenever unemployment is held below the natural rate by expansionary aggregate demand policy, inflation continually accelerates because the initially perceived increase in real wages is always being wiped out by the adaptation of expectations (and information) to the experience of inflation and must be continually reestablished with ever-larger increases in the nominal wage. ${ }^{3}$ Conversely, so long as unemployment is kept above the natural rate, inflation will decelerate.

Rational expectations. The rationality of economic agents, whose pursuit of unexploited opportunities for mutual trade provides the marketclearing pressure in the accelerationist model, requires that expectations of future prices be based not on adaptation to past inflation, but on all the information available. Because in a world of rapidly clearing markets inflation can be viewed as solely a monetary phenomenon, rational agents

3. Various versions of an accelerationist process have been elaborated, involving different ways in which relative prices are based on expectations or data about the rate of general inflation that adapt with a lag to actual inflation experience; see Milton Friedman, "The Role of Monetary Policy," American Economic Review, vol. 58 (March 1968), pp. 1-17; Edmund S. Phelps and others, Microeconomic Foundations of Employment and Inflation Theory (W. Norton and Co., Inc., 1970); and Robert E. Lucas, Jr., "Expectations and the Neutrality of Money," Journal of Economic Theory, vol. 4 (April 1972), pp. 103-24. 
can be modeled as forecasting inflation on the basis of their forecast of monetary policy, which in turn is heavily based on the systematic past behavior of the monetary authorities. If the coefficients that relate current inflation to past inflation rates sum to unity, for example, it is not because this is inherent in the nature of expectations-rather it is the result of past experience with inflationary monetary policy. (Although rational expectations theorists are monetarist in persuasion, the effect of expected fiscal policy on inflationary expectations can be included without changing anything significant for the purposes of this paper.)

One particular implication of rational expectations theory should be noted at this stage inasmuch as it is especially relevant to a long-term historical analysis of inflation. According to the theory, the response of inflation to an expected change in nominal aggregate demand is prompt and substantial. But if economic agents, on the basis of past experience, expect monetary (and fiscal) policy to be dedicated to the pursuit of employment stability, and to turn expansive at the first sign of an economic downturn, they will expect any decline in nominal demand to be merely a transient one and prices will behave accordingly. According to the rational expectations theorists, the small response of inflation to changes in aggregate demand in mainline models-George Perry's term embracing the broad class of models with structural inflation inertia-is therefore misleading. The large and prompt potential response of inflation to a change in nominal demand, which is a property of the market-clearing economic system, has been masked in the aggregate data by the expectational consequences of employment-oriented countercyclical policy. Thus this theory implies that, in periods when such policies were absent, the response of inflation to changes in nominal aggregate demand should have been considerably larger than that predicted by the coefficients on unemployment, the change in unemployment, or related variables typically estimated in the mainline models.

The debate among the competing views of the inflationary process hinges partly on the role of expectations in the determination of current prices and on alternative hypotheses about how expectations are formed. The relevant variables are not observable and must be inferred indirectly. Actual prices, for example, must be supposed to respond with short or long lags to changes in demand variables, and weakly or strongly to changes in expected prices; these in turn respond with greater or lesser strength to past inflation or to expected aggregate demand policy-expec- 
tations that may on occasion be in the process of gradually adapting to the installation of a new policy regime.

Seeking to reach conclusions about expectations by observing regression coefficients on lagged price or wage variables, by algebraic manipulation of coefficients on lagged real disequilibrium variables, or by using residuals to classify economic policy into its systematic and surprise components is one way to proceed, but it is surely a very chancy business. As Bennett McCallum recently put it in a nice bit of understatement, ". . . it is not a trivial matter to interpret the speed of [inflation] response to unobserved variables in a stochastic setting." Analysis and historical comparison of the cyclical characteristics of inflation ought, therefore, to be a useful supplement to the more usual econometric analysis of quarterly or annual data as an additional means of inferring if and how such unobserved variables influence inflation. For example, has the sensitivity of inflation to cyclical expansions and contractions of demand tended to remain unchanged during clearly different monetary policy regimes? Has the expansion of employment typically been maintained during cyclical expansions at the cost of accelerating inflation?

\section{The Cyclical Response of Inflation to Changes in Aggregate Demand}

For reasons summarized above and elaborated in the discussion that follows, the business cycles of the past eighty years are divided into three groups in the present study: peacetime cycles through 1966 (1901-14, 1924-40, 1950-66); wartime cycles and postwar adjustments (1916-22, 1941-49); and the period since 1966, which includes the last three years of the 1961-69 expansion. In addition, results for the peacetime cycles are often shown in two versions: including and excluding the Great Depression.

The cyclical sensitivity of inflation to changes in aggregate demand cannot be measured by partitioning changes in nominal GNP between price and quantity changes and then comparing prewar with postwar cycles. If there is any momentum from past inflation (or, in another interpretation, if there is a relatively persistent inflation norm that influences current rates of wage and price increase), partitioning will underestimate the sensitivity of inflation in contractions relative to expansions

4. Bennett T. McCallum, "Rational Expectations and Macroeconomic Stabilization Policy: An Overview," Journal of Money, Credit and Banking, vol. 12 (November 1980), p. 734. 
and in periods in which inherited inflation or inflation norms are large relative to other periods.

This problem can be sharply reduced by comparing the acceleration and deceleration of inflation with that of nominal GNP as it swings from expansion to contraction and back, so long as the inflation norm is not changing sharply from one cycle to the next.

As an initial formulation, let the aggregate supply curve be expressed as follows, with all variables measured as average annual percent changes over a business-cycle expansion or contraction: ${ }^{5}$

$$
p=\beta\left(q-q^{*}\right)+p_{A}+p_{N}
$$

where

$p=$ rate of change in GNP deflator

$p_{A}=$ direct impact of autonomous supply shocks on the rate of change in the GNP deflator (or other price measure)

$p_{N}=$ inflation norm

$q=$ rate of change in real GNP

$q^{*}=$ rate of change in potential GNP.

The aggregate supply curve (equation 1) is the first-difference form of either a modified early Keynesian or a speed-limit model of inflation: the change in prices is equal to the norm rate of inflation plus any direct impact of autonomous supply shocks plus a component that depends on the change in output relative to potential. This formulation can explain much (but, as shown below, not all) of the behavior of inflation during expansions and contractions of peacetime cycles through the mid-1960s.

The inflation norm, as suggested by Okun and Perry, is a relatively stubborn and not easily changed underlying rate of inflation, around which demand and supply developments generate deviations in the actual inflation rate. ${ }^{6}$ The norm rate of inflation is "pure" inflation; deviations around the norm both result from and give rise to changes in resource allocation. The hypothesis is that the norm changes in response to significant and persistent deviations in actual inflation from the norm but does not adapt continuously and does not shift significantly in response to

5. Throughout this paper uppercase letters represent levels of a variable; lowercase, rates of change.

6. Arthur M. Okun, Prices and Quantities: A Macroeconomic Analysis (Brookings, 1981 ), and George L. Perry, "Inflation in Theory and Practice," BPEA, 1:1980, pp. 207-41. 
moderate deviations of actual inflation from the norm unless those deviations are maintained for long periods (as happened in the late 1960s).

There is no attempt here to make a doctrinal issue about the concept of an inflation norm. Rather, it is a useful way of expressing the proposition that the complex of backward- and forward-looking forces that influenced current wage and price setting in most peacetime cycles since 1900 tended to persist with only modest changes across a number of cycles.

Inflationary supply shocks can be of two kinds: a leftward shift in the supply schedule of some major sector like food or energy, or a noncyclical change in productivity growth. Supply shocks have four kinds of effects: given a "sticky" $p_{N}$ they raise the aggregate supply curve; while this is occurring, output growth is depressed relative to the change in nominal aggregate demand; in turn, depending on the magnitude of $\beta$ in equation 1 above, some demand-induced offsetting reduction in the price level occurs if the growth in nominal GNP is unchanged; finally, to the extent that any of the transitional inflation from the price-level adjustment becomes incorporated into the norm, there is a long-term increase in the amount of nominal GNP change needed to achieve any given real growth. If a period of reduced productivity growth is not merely the transition phase of a one-time downward shift in the level of productivity, but a long-term reduction in growth, two additional (and related) effects occur: the actual and norm rate of price inflation rises relative to the actual and norm rate of wage inflation, and the rate of growth of potential slows so that aggregate demand must subsequently rise more slowly than before if inflationary demand pressures are to be avoided. Finally, if the reduction in productivity growth initially leads to a period of higher price inflation, because demand restraints are not sufficient to offset the initial upward shift in the aggregate output supply curve, the wage norm may be ratcheted upward.

Expressing $p$ as a function of nominal GNP change yields

$$
p=\frac{\beta}{1+\beta}\left[y-\left(q^{*}+p_{A}+p_{N}\right)\right]+p_{A}+p_{N},
$$

where $y$ is the growth rate of nominal GNP. Assuming no autonomous supply shocks, inflation deviates from the norm in proportion to the excess of nominal GNP changes over the change in potential GNP evaluated at the norm rate of inflation. 
Table 1. Moving Average of Change in GNP Deflator, Peacetime Cycles Excluding the Great Depression, 1901-66

Percent per year

\begin{tabular}{rrrrrr}
\hline Year & $\begin{array}{c}\text { Three-year } \\
\text { average }\end{array}$ & $\begin{array}{c}\text { Five-year } \\
\text { average }\end{array}$ & Year & $\begin{array}{c}\text { Three-year } \\
\text { average }\end{array}$ & $\begin{array}{c}\text { Five-year } \\
\text { average }\end{array}$ \\
\hline 1901 & 2.4 & 2.1 & 1949 & 6.3 & 7.4 \\
1902 & 2.4 & 2.7 & 1950 & 2.7 & 7.3 \\
1903 & 1.3 & 2.3 & 1951 & 2.6 & 5.5 \\
1904 & 1.9 & 1.9 & 1952 & 3.4 & 3.2 \\
1905 & 1.4 & 1.4 & 1953 & 3.2 & 2.1 \\
1906 & 2.0 & 2.1 & 1954 & 1.4 & 2.6 \\
1907 & 3.0 & 2.3 & 1955 & 1.7 & 2.6 \\
1908 & 2.1 & 1.9 & 1956 & 2.2 & 1.9 \\
1909 & 2.2 & 2.3 & 1957 & 2.9 & 2.3 \\
1910 & 1.8 & 2.5 & 1958 & 2.8 & 2.3 \\
1911 & 1.4 & 1.6 & 1959 & 2.5 & 2.6 \\
1912 & 1.9 & 1.7 & 1960 & 1.9 & 2.5 \\
1913 & 0.8 & 1.7 & 1961 & 1.6 & 2.0 \\
1914 & 1.8 & 1.3 & 1962 & 1.5 & 1.7 \\
& & & 1963 & 1.4 & 1.7 \\
1923 & -7.3 & -2.4 & 1964 & 1.6 & 1.5 \\
1924 & -1.6 & -1.4 & 1965 & 1.7 & 1.6 \\
1925 & 1.5 & -4.2 & 1966 & 2.3 & 2.1 \\
1926 & -0.3 & -0.8 & & & \\
1927 & -0.7 & 0.1 & & & \\
1928 & -1.0 & -0.5 & & & \\
1929 & -0.5 & -0.2 & & & \\
\hline
\end{tabular}

Sources: Before 1909 the Kendrick series for GNP were used, as published in U.S. Bureau of the Census, Long Term Economic Growth, 1860-1965 (U.S. Government Printing Office, 1966), p. 166. After 1909 the data are from the national income and product accounts.

As long as $p_{A}$ is relatively unimportant and neither the norm nor potential growth change significantly from one observation to the next, then

$$
\Delta p / \Delta y=\lambda
$$

where $\lambda$ is $\beta /(1+\beta)$, and is referred to here as the flexibility coefficient. While changes in $p_{N}$ or the occurrence of supply shocks will reduce the accuracy of $\Delta p / \Delta y$ as an index of the cyclical sensitivity of inflation to changes in aggregate demand, so long as the shocks or norm changes are infrequent and modest in size, the errors will not be large. Table 1 shows three- and five-year moving averages of the average annual change in the GNP deflator during the peacetime cycles through 1966 excluding the Great Depression. Except for the years when the moving averages were 
Table 2. Cyclical Impact of Farm Prices, Selected Periods, 1900-66

Percentage points

\begin{tabular}{cc}
\hline Period & $\begin{array}{c}\text { Change in GNP deflator } \\
\text { minus change in private } \\
\text { nonfarm deflator }\end{array}$ \\
\hline $1900-03$ & $0.7(0)^{\mathrm{a}}$ \\
$1904-07$ & 0.2 \\
$1908-10$ & 0.9 \\
$1911-13$ & 0.3 \\
$1924-26$ & 0.6 \\
$1927-29$ & -0.1 \\
$1949-53$ & -0.2 \\
$1954-57$ & 0.0 \\
$1958-59$ & -0.1 \\
$1960-66$ & 0.3
\end{tabular}

Source: Same as table 1 for GNP deflator and after 1909 for nonfarm deflator. See appendix A for earlier data on farm prices.

a. For 1901-03.

affected by the immediate postwar inflation-when, as I argue below, actual inflation rates were not incorporated into either the norm or longterm expectations - the data suggest that shifts in $p_{N}$ were unlikely to have been frequent. And, as table 2 shows, the direct contribution of relative farm prices to the GNP deflator was also modest in all the cyclical expansions except three (1900-03, 1908-10, and 1924-26), and in the first of those the rise in farm prices was partially reversed during the expansion.

Before examining regression estimates of the value of $\lambda$, an alternative measure of its value was calculated. By averaging the values of $p$ and $y$ in expansions and subtracting them from the averages of $p$ and $y$ in contractions, a "mean" $\Delta p / \Delta y$ ratio was calculated for various periods. ${ }^{7}$ This mean should provide a useful rough measure of $\lambda$ so long as any change in $p_{N}$ affects an equal number of expansions and contractions. This condition appeared to have been met in the prewar period. But in the postwar years through 1966 - the period being examined - there was an apparent downward shift in $p_{N}$ in the early $1960 \mathrm{~s}$, which tended to lower the calculated mean $\Delta p / \Delta y$. To calculate the mean $\Delta p / \Delta y$ for the postwar period,

7. The averages for $p$ and $y$ were unweighted; each expansion and contraction is a unit of observation. 
Table 3. Change in Inflation and Nominal GNP Growth, Prewar and Postwar Peacetime Contractions, 1900-66, Total Economy and Nonfarm Sector ${ }^{\mathrm{a}}$

Percent change per year or ratio

\begin{tabular}{|c|c|c|c|c|c|c|}
\hline \multirow[b]{2}{*}{ Period and measure } & \multicolumn{3}{|c|}{ Total economy } & \multicolumn{3}{|c|}{ Private nonfarm sector ${ }^{\mathrm{b}}$} \\
\hline & $p$ & $y$ & $\Delta p / \Delta y$ & $p$ & $y$ & $\Delta p / \Delta y$ \\
\hline \multicolumn{7}{|c|}{$\begin{array}{c}\text { Prewar cycles (excluding } \\
\text { Great Depression) }\end{array}$} \\
\hline Expansions & 1.7 & 7.4 & $\ldots$ & 1.2 & 7.8 & $\ldots$ \\
\hline Contractions & -0.7 & -2.1 & $\ldots$ & -0.4 & -2.7 & $\ldots$ \\
\hline Change $(\Delta p, \Delta y)$ & 2.3 & 9.5 & 0.25 & 1.6 & 10.5 & 0.15 \\
\hline \multicolumn{7}{|l|}{$\begin{array}{c}\text { Great Depression } \\
(1929-41)\end{array}$} \\
\hline Expansions & $\ldots$ & $\ldots$ & $\ldots$ & 1.6 & 11.5 & $\ldots$ \\
\hline Contractions & $\ldots$ & $\ldots$ & $\ldots$ & -2.2 & -10.8 & $\ldots$ \\
\hline Change $(\Delta p, \Delta y)$ & $\ldots$ & $\ldots$ & $\ldots$ & 3.8 & 22.3 & 0.17 \\
\hline \multicolumn{7}{|l|}{ Postwar cycles } \\
\hline Expansions & 2.8 & 8.0 & $\ldots$ & 2.8 & 8.6 & $\ldots$ \\
\hline Contractions & 1.5 & 1.7 & $\ldots$ & 1.4 & 1.2 & $\ldots$ \\
\hline Change $(\Delta p, \Delta y)$ & 1.2 & 6.3 & 0.19 & 1.4 & 7.4 & 0.19 \\
\hline
\end{tabular}

Source: Same as table 1 for total GNP; see appendix A for private nonfarm GNP.

a. The $p$ and $y$ variables denote the average annual rate of change in the GNP deflator and in nominal GNP, respectively, during expansions or contractions.

b. GNP less gross product originating in the farm and government. For 1900-09, for which estimates of government GNP in current dollars are unavailable, nonfarm GNP is used. See appendix A. Here and in other tables, totals may not add due to rounding.

c. The measures of $p, y, \Delta p$, and $\Delta y$ are based on calculations that adjusted the 1961-66 data for a downward norm shift. See the text for an explanation.

the average values for $p$ and $y$ in 1961-66 were each raised by 1.0 percentage point to adjust for the downward shift in the inflation norm. ${ }^{8}$

The results of this calculation of the mean are shown in table 3 . The data in this table indicate that for the nonfarm economy there was no substantial change between the pre-1929 and postwar periods in the average acceleration or deceleration of inflation relative to changes in nominal GNP growth. (The postwar $\Delta p / \Delta y$ ratios calculated without a norm shift adjustment were 0.16 for both the total GNP and the private nonfarm GNP.) In neither period was the response of inflation large. In the prewar cycles real farm prices moved procyclically. The price support programs after the Second World War ended this phenomenon. As a

8. As discussed below, the norm, as reflected in the nonfarm deflator, was assumed to fall from 2.5 to 1.5 between the 1949-60 and the 1961-66 periods. 
consequence, the relative acceleration and deceleration of the overall GNP deflator was somewhat larger in the prewar period than in postwar cycles. The swing in inflation, relative to the swing in nominal GNP, was little different in the cyclical phases of the Great Depression than in prewar or postwar cycles, a surprising result given the huge size of the swings and the level of unemployment at the troughs in 1933 and 1938.

"Weighted deceleration" measures can be calculated to show what contribution contractions in the economy have made toward slowing inflation. They are generated by multiplying the average annual deceleration that characterized contractions in each period by the relative number of years spent in contraction. In the prewar period, fourteen years were spent in expansion and six in contraction, so the deceleration is multiplied by the ratio $6 / 14(0.43)$. The ratio in the postwar period is half that large $(0.21)$. While price flexibility relative to changes in demand was no smaller in the postwar period than in the prewar years (for nonfarm GNP), high employment policies reduced the deceleration of inflation in two ways: deceleration of nominal GNP averaged about two-thirds as large during recessions ( -7.4 percent versus -10.5 percent), and occurred only half as frequently. Thus in terms of determining the average rate of inflation for the period as a whole, deceleration of nominal GNP contributed only one-third as much as in the prewar period.

These calculations implicitly assume that the cyclical deceleration did not substantially affect the $p_{N}$ of the subsequent expansion. I argue below that this is a reasonable assumption. But to the extent that the norm was kept higher than it otherwise would have been, the "effective" demand deceleration of the postwar period was even less than one-third as great relative to prewar years.

The rough stability between prewar and postwar periods of the coefficient linking changes in inflation to changes in aggregate demand and the sharp reduction in the variability of aggregate demand in the postwar period are both strikingly indicated in another way: in the 1954-66 period the ratios of the standard deviations of nominal GNP, real GNP, and the deflator to the standard deviations in prewar years (1900-14 and 1923-29) were all 0.5.9

9. Based on data for the private nonfarm sector. See also the means and standard deviations for various subperiods between 1890 and 1980 given by Gordon, "Price Inertia," table 3. 


\section{REGRESSION EQUATIONS}

In estimating the response of inflation to changes in aggregate demand through ordinary least squares regressions there are problems of potential bias from both measurement and specification errors.

If changes in nominal GNP are truly exogenous, positive errors in the price terms, in the stochastic version of equation $1 \mathrm{a}$, will show up as negative changes in real GNP and vice versa. In that case, fitting $p$ against $y$ (equation 1a) will give an unbiased estimate of $\lambda$, and fitting $p$ against $q$ (equation 1) will give a downward bias to the estimate of $\beta$ and hence of $\lambda$. But specifying nominal GNP to be completely exogenous requires some stringent conditions. It would require, for example, that the monetary and fiscal authorities be committed to a fixed path of nominal GNP and neither overshoot nor undershoot when price surprises take place. Even the direction of possible bias is likely to be unknown; over a period as long as a business cycle, price increases that are larger than normal may induce policy responses that subsequently depress nominal GNP as well as real GNP.

In fitting $p$ to $q$, an additional measurement problem may also be present. The majority of the estimates of real GNP are made by deflating estimates of nominal expenditures with prices. Measurement errors in prices produce exactly offsetting quantity errors, biasing downward the $\lambda$ estimates from equation 1.

Finally and most important, it is clearly wrong to fit $p_{t}$ against $y_{t}$ (as distinct from $q_{t}$ ) when there is reason to believe that some component of $p$ is, in period $t$, exogenous to movements in aggregate demand. The discussion above pointed out that if some part of inflation represents inherited momentum or a relatively sticky norm, then fitting $p_{t}$ to $y_{t}$ will yield a spuriously large coefficient on $y_{t}$; even if $y_{t}$ is strictly exogenous, $p$ will be regressed on some component of $p$. Hence the necessity arises either to operate with second differences of prices $(\Delta p=\lambda \Delta y)$ or to specify the dependent variable as a deviation from the norm or the inherited inflation rate $\left(p-p_{N}\right){ }^{10}$

10. Gordon's recent papers use as the main dependent variable the excess of the growth of nominal GNP over potential GNP $\left(y-q^{*}\right)$, compared to the measure $\left(y-q^{*}-p_{N}\right)$ used in this paper. See Robert J. Gordon, "A Consistent Characterization" and "Output Fluctuations and Gradual Price Adjustment." 
To test the sensitivity of the $\lambda$ coefficient to alternative specifications and possible measurement errors, three alternative variables were used to measure aggregate demand: $y, q$, and two new variables, $n$ and $n^{*}$ rates of change in actual and potential aggregate hours worked. The new variables are surrogates for $q$ and $q^{*}$ that are free of the problem of bias from measurement error. Both the equation 2 format $(\Delta)$ and the equation 1 format were used, resulting in the following variants:

$$
\begin{array}{clrl}
\begin{array}{c}
\text { Independent } \\
\text { variable }
\end{array} & & \\
y & & \text { Equation } \\
& \Delta p & =a_{0}+\lambda \Delta y \\
q & \left(p-p_{N}\right) & =a_{1}+\lambda\left(y-q^{*}-p_{N}\right) \\
\Delta p & =b_{0}+\beta \Delta q \\
& & \left(p-p_{N}\right) & =b_{1}+\beta\left(q-q^{*}\right) \\
\Delta p & =c_{0}+\delta \Delta n \\
& \left(p-p_{N}\right) & =c_{1}+\delta\left(n-n^{*}\right)
\end{array}
$$

The estimated coefficients were then used to calculate alternative estimates of $\lambda$, the response of inflation to changes in nominal GNP. The relation between the coefficients is

$$
\begin{gathered}
\lambda_{y}=\lambda, \quad \lambda_{q}=\frac{\beta}{1+\beta} \\
\lambda_{n}=\frac{\delta(1-\phi)}{1+\delta(1-\phi)},
\end{gathered}
$$

where the subscripts on $\lambda$ represent the aggregate demand variable used in estimating $\lambda$. The coefficient $\phi$ relates $n$ to $q$ from a simple productivity equation of the form

$$
\begin{aligned}
\left(x-x^{*}\right) & =\phi\left(q-q^{*}\right), \\
x & =(q-n),
\end{aligned}
$$

where $x$ and $x^{*}$ are actual and potential productivity change. ${ }^{11}$

The choice of $p_{N}$ is controversial, but as table 1 suggests, the possibilities for error are not large. On the basis of arguments by Okun and

11. This productivity equation (with cycle phases as the observation period) yielded a $\phi$ of 0.36 in the prewar cycles and 0.32 when prewar and postwar cycles were combined. 
Perry and evidence developed below, $p_{N}$ is fairly stable. It does not change easily. It is not a mechanical concept, responding smoothly to some weighted average of past data. Thus, rather than use the actual moving average of table 1 , which suggests a fairly smooth adaptive process, I kept $p_{N}$ the same through the major subperiods of the prewar and postwar cycles, estimating it by the average rate of price change over the subperiod (ignoring the small price decline of the 1920s). While economic agents obviously did not know the averages before they were established, the averages do not differ much from a four- or five-year moving average (except during the periods immediately following the two postwar adjustments, when, I later argue, the actual price changes were not indicators of longer-term expectations). The estimated $p_{N}$ and $q^{*}$ in percent per year are shown below for the private nonfarm economy. ${ }^{12}$

$\begin{array}{ccc} & p_{N} & q^{*} \\ 1900-14 & 1.3 & 4.1 \\ 1923-29 & 0.0 & 3.8 \\ 1949-60 & 2.5 & 3.9 \\ 1961-66 & 1.5 & 3.8\end{array}$

The first point about the regression estimates of $\lambda$ for nonfarm GNP, shown in table 4 , is that they are relatively close together. By any measure, $\lambda$ has always been relatively small. The second point is that inclusion of the postwar cycles (through 1966) does not change the estimates at all. The $\Delta p$ regressions are also close to the means shown in table 3 . The third point is that the value of $\lambda$ is quite insensitive to whether $y, q$, or $n$ is used to estimate it. The precise values of the coefficients in the equations based on aggregate hours worked are undoubtedly affected by the crudity of the productivity equation used to identify the structural coefficient in the formulation based on hours worked. Nevertheless, the fact that equations based on aggregate hours worked give about the same value as the $y$ and $q$ formulations suggests that the $\lambda$ estimates generated by $q$ are not being dominated by collinearity between measurement errors in $p$ and $q$. The $\lambda$ estimates from the first-difference formulation, using $p-p_{N}$, are univer-

12. For the prewar period, $q$ * was estimated in two constant segments (1900-14 and 1923-29) as the growth in private nonfarm GNP between years with roughly similar unemployment, using an Okun's law adjustment for the remaining differences. In each postwar subperiod the average growth in the series on potential GNP prepared by the Council of Economic Advisers was used; potential for private nonfarm GNP was estimated by subtracting actual government and farm GNP from potential total GNP. 
Table 4. Response of Price Inflation to Changes in Aggregate Demand in Peacetime Cycles, Private Nonfarm Economy, 1900-66 ${ }^{\mathrm{a}}$

\begin{tabular}{ccc}
$\begin{array}{c}\text { Period and method } \\
\text { used to estimate } \lambda\end{array}$ & $\begin{array}{c}\text { Form of dependent } \\
\text { variable }\end{array}$ & Value of $\lambda$ \\
\hline Prewar cycles & & \\
$\lambda_{y}$ regression & $\Delta p$ & $0.15(0.73)$ \\
& $\left(p-p_{N}\right)$ & $0.12(0.39)$ \\
$\lambda_{q}$ regression & $\Delta p$ & $0.14(0.63)$ \\
& $\left(p-p_{N}\right)$ & $0.10(0.23)$ \\
$\lambda_{n}$ regression & $\Delta p$ & $0.13(0.51)$ \\
& $\left(p-p_{N}\right)$ & $0.09(0.18)$ \\
Prewar and postwar cycles & & \\
$\lambda_{y}$ regression & $\Delta p$ & $0.15(0.75)$ \\
& $\left(p-p_{N}\right)$ & $0.13(0.47)$ \\
$\lambda_{q}$ regression & $\Delta p$ & $0.15(0.66)$ \\
& $\left(p-p_{N}\right)$ & $0.11(0.32)$ \\
$\lambda_{n}$ regression & $\Delta p$ & $0.13(0.60)$ \\
& $\left(p-p_{N}\right)$ & $0.10(0.29)$ \\
\hline
\end{tabular}

Sources: Author's computations based on data as described in appendix A.

a. Excluding the Great Depression.

b. The $\lambda=\Delta p / \Delta y$ denotes changes in the rate of inflation relative to changes in aggregate demand. The subscripts $y, q$, and $n$ represent the aggregate demand variable used in estimating $\lambda$, namely the rates of change in nominal GNP, real GNP, and aggregate hours worked, respectively. For the regression estimates the numbers in parentheses are the $R^{2}$ of the regression. See text for the form of the $\lambda_{y}, \lambda_{q}$, and $\lambda_{n}$ regressions.

sally lower than their counterparts from second-difference equations ( using $\Delta p$ ).

In the next two sections the formulation developed above is applied to a cyclical analysis of wholesale and consumer prices and wages.

\section{CYCLICAL FLEXIBILITY OF WHOLESALE}

\section{AND RETAIL PRICES}

In a careful and detailed analysis, Phillip Cagan demonstrates that the magnitude of cyclical fluctuations in wholesale prices declined sharply between the prewar and postwar periods. ${ }^{13}$ In particular, the magnitude of the deceleration of wholesale prices from cyclical expansion to contraction has declined substantially. Cagan's comparison of price movements in mild cycles led him to conclude that wholesale prices have be-

13. Phillip Cagan, "Changes in the Recession Behavior of Wholesale Prices." 
Table 5. Summary Measures of Cyclical Price Flexibility, Peacetime Cycles, 1900-66 ${ }^{\mathrm{a}}$

\begin{tabular}{|c|c|c|c|c|c|c|}
\hline \multirow[b]{2}{*}{ Period and measure } & \multicolumn{2}{|c|}{ Deflator } & \multicolumn{2}{|c|}{$\begin{array}{l}\text { Consumer } \\
\text { price index }\end{array}$} & \multicolumn{2}{|c|}{$\begin{array}{c}\text { Wholesale } \\
\text { price index }\end{array}$} \\
\hline & $G N P$ & $\begin{array}{l}\text { Private } \\
\text { nonfarm }\end{array}$ & Total & $\begin{array}{l}\text { Exclud- } \\
\text { ing food }\end{array}$ & Total & $\begin{array}{c}\text { Indus- } \\
\text { trial }\end{array}$ \\
\hline \multicolumn{7}{|c|}{ Mean annual change (percent per year) } \\
\hline \multicolumn{7}{|l|}{ Prewar cycles } \\
\hline Expansions & 1.7 & 1.2 & 1.6 & 0.4 & 2.6 & 2.1 \\
\hline Contractions & -0.7 & -0.4 & -0.7 & -0.6 & -3.5 & -6.1 \\
\hline Change $(\Delta p)$ & 2.3 & 1.6 & 2.3 & 1.0 & 6.1 & 8.2 \\
\hline \multicolumn{7}{|l|}{ Postwar cycles } \\
\hline Expansions & 2.7 & 2.8 & 2.0 & 2.3 & 1.7 & 2.4 \\
\hline Contractions & 1.5 & 1.4 & 1.6 & 1.5 & 0.6 & 0.2 \\
\hline Change $(\Delta p)$ & 1.2 & 1.4 & 0.4 & 0.7 & 1.2 & 2.2 \\
\hline \multicolumn{7}{|c|}{ Flexibility coefficients $(\Delta p / \Delta y)$} \\
\hline Prewar cycles & 0.25 & 0.15 & 0.24 & 0.10 & 0.64 & 0.78 \\
\hline Postwar cycles & 0.19 & 0.19 & 0.06 & 0.10 & 0.18 & 0.29 \\
\hline
\end{tabular}

Source: GNP and private nonfarm deflators-table 3; wholesale price index and consumer price index since 1913-U.S. Bureau of Labor Statistics; consumer price index from 1900 to 1913-Albert Rees, Real Wages in Manufacturing, 1890-1914 (Princeton University Press, 1961), p. 74.

a. Excluding the Great Depression. Flexibility coefficients for private nonfarm deflator, industrial wholesale price index, and consumer price index excluding food are based on private nonfarm GNP; all others, on total GNP.

come less flexible not only absolutely but in relation to changes in aggregate demand.

Mean $\Delta p / \Delta y$ ratios for wholesale and consumer prices are shown in table 5, based on calculations that adjust the data, as explained earlier, for a downward norm shift in 1961-66. From the last two columns of table 5 it is clear that Cagan's findings about the absolute decline in wholesale price flexibility also hold up in terms of wholesale price changes relative to changes in nominal GNP - the flexibility coefficient for the wholesale price index declined substantially between the prewar and postwar periods. The flexibility of the total consumer price index also declined sharply. Virtually all the decline in the consumer price index (CPI), however, was due to reduced flexibility in the food component. The flexibility of the CPI excluding food was already very small in the prewar period and remained at about the same level in the postwar years. ${ }^{14}$

14. The greater prewar flexibility of farm prices had a proportionately greater effect on the total CPI than on the total GNP deflator since the weight of farm prices was larger in the CPI than in the deflator. 
How can Cagan's findings about wholesale prices be reconciled with the evidence that price flexibility for the private nonfarm deflator and for the CPI less food has not changed significantly and that the flexibility of the total GNP deflator has only fallen slightly? To some extent the reduction in wholesale price flexibility may be a statistical mirage. In earlier years commodities with flexprice characteristics (such as farm products, some metals, and raw materials generally) or semi-flex price characteristics (like cotton textiles, lumber) made up a larger fraction of the index weights. And before 1947 the index did not include any significant coverage of machinery and equipment, whose prices (especially the list prices that are entered in the wholesale price index, WPI) are quite sticky. Appendix B to this paper discusses the reasons why it is unlikely that the decline in the responsiveness of wholesale prices was wholly due to changes in the statistical composition of the index, but reflects, at least to some extent, a real decline in their flexibility relative to changes in aggregate demand.

The change in the cyclical behavior of wholesale prices cannot be attributed principally to changing wage behavior. As discussed below, wages have probably become less cyclically sensitive, but the change has been far smaller than in the case of wholesale prices. Even in the prewar period the cyclical flexibility of wages was far less than that of wholesale prices.

Other than perishable crude foods and a few smaller items, flexprice markets for consumer goods probably never existed. Customer markets for consumer goods and services have always been the usual arrangement. But a number of factors may have caused many wholesale markets to take on more of the characteristics of customer markets. Products have become less homogenous, more differentiated, and more complex. Improved transportation has led to the growth of national brand names, nationwide markets, customer servicing by the manufacturer, supplierowned retail outlets, and the need for manufacturers to price with consumer loyalty in mind. The spread of consumer credit supplied by goods producers has worked in the same way. And the growth of large national and regional retail chains, which sell in customer markets and buy in large quantities, often under longer-term contracts from suppliers in national markets, may have helped push back to the wholesale level the customerprice behavior that has always characterized consumer markets. 
THE BEHAVIOR OF WAGES

Attempts to measure the cyclical flexibility of wages are confounded by the problem that, for most of the period covered, no true wage index exists. For the postwar period aggregate wage indexes are available that exclude overtime in manufacturing and adjust for shifts in employment among industries. But within individual firms the average hourly earnings statistic is unweighted. Changes in reported average hourly earnings are influenced not only by changes in wage or salary rates, but by changes in the skill mix within the firm and by the effect of layoffs and recalls in a seniority-based system on average pay in firms with pay systems related to length of employment. An inspection of the distribution of average hourly earnings changes by individual establishments within specific industries suggests that the nonwage factors have an important effect on the movement of reported average hourly earnings during cycles.

If the errors introduced by the nonwage influences were highly systematic across the eighty years of cycles that this paper analyzes, at least the relative wage flexibility of prewar versus postwar cycles would be ascertainable. But there is surely a strong likelihood that layoffs and hiring in a seniority-based system and pay according to length of employment were a smaller factor in the early years when unions were far less important, both directly in numbers and indirectly in their influence on nonunion compensation structures. And the cyclical impact of such pay and layoff practices on average hourly earnings is unambiguous-it lowers the reported deceleration of wages during contractions. ${ }^{15}$ The wage-flexibility coefficients shown in table 6 for various measures of wage and compensation change should be interpreted with these limitations in mind.

For the private nonfarm economy as a whole, data on wage changes are scant in the prewar period. Lebergott's series for "average annual earnings of full-time equivalent employees" was divided by a series developed by Kendrick and the Bureau of Labor Statistics (BLS) on average hours worked to derive a series for average hourly earnings. ${ }^{16}$ The underlying

15. The new occupation-weighted employment cost index has only been available since late 1975, and, in any event, it is not clear that the occupation-weighted structure completely eliminates the problem.

16. Full-time equivalent earnings are defined as earnings of full-time employees working at weekly hours customary to the time and industry. Thus annual full-time 
Table 6. Cyclical Wage Flexibility, Peacetime Cycles, 1900-66

Percent change per year or ratio

\begin{tabular}{|c|c|c|c|}
\hline \multirow[b]{3}{*}{ Period and measure } & \multicolumn{3}{|c|}{ Average hourly earnings } \\
\hline & \multicolumn{2}{|c|}{ Private nonfarm } & \multirow{2}{*}{$\frac{\text { Manufacturing }}{{\text { Rees } / B L S^{\mathrm{b}}}^{\text {M }}}$} \\
\hline & $\begin{array}{l}\text { Lebergott, } \\
\text { adjusted }^{\mathrm{a}}\end{array}$ & Wojtinsky & \\
\hline \multicolumn{4}{|l|}{ Prewar cycles } \\
\hline Expansions & 3.3 & 2.6 & 3.0 \\
\hline Contractions & 1.8 & 1.3 & 0.4 \\
\hline Change $(\Delta w)$ & 1.5 & 1.3 & 2.6 \\
\hline \multirow[t]{3}{*}{ Flexibility coefficients ${ }^{c}(\Delta w / \Delta y)$} & 0.15 & 0.12 & 0.25 \\
\hline & \multicolumn{3}{|c|}{ Adjusted average hourly earnings } \\
\hline & $\begin{array}{c}\text { Adjusted } \\
\text { compensation }^{\mathrm{d}}\end{array}$ & $\begin{array}{c}\text { Private } \\
\text { nonfarm }^{\mathrm{d}}\end{array}$ & Manufacturinge \\
\hline \multicolumn{4}{|l|}{ Postwar cycles } \\
\hline Expansions & 4.8 & 4.4 & 4.4 \\
\hline Contractions & 4.0 & 3.7 & 3.3 \\
\hline Change $(\Delta w)$ & 0.8 & 0.8 & 1.1 \\
\hline Flexibility coefficients $^{\mathrm{c}}(\Delta w / \Delta y)$ & 0.11 & 0.10 & 0.16 \\
\hline
\end{tabular}

Sources: Lebergott series-U.S. Bureau of the Census, Historical Statistics of the United States: Colonial Times to 1970 (GPO, 1975), pt. 1, series 724, tables D722-27, p. 164, and Long Term Economic Growth, 1860-1965, pp. 192-93; Wojtinsky series-W. S. Wojtinsky and Associates, Employment and Wages in the United States (The Twentieth Century Fund, 1953), table 16, p. 584; Rees series-Albert Rees, "Patterns of Wages, Prices and Productivity," in Charles A. Myers, ed., Wages, Prices, Profits and Productivity (American Assembly, Columbia University, 1959), pp. 11-35; and postwar series-Bureau of Labor Statistics and national income and product accounts.

a. The Lebergott series for average annual earnings for full-time employees was divided by a KendrickBLS series on average hours worked to derive an average hourly earnings series.

b. Rees series through 1919; U.S. Bureau of Labor Statistics series since then.

c. Calculated using the deceleration of private nonfarm GNP.

d. Adjusted for overtime in manufacturing and for interindustry employment shifts, as explained in the text.

e. Adjusted for overtime. From 1964 on, a manufacturing series adjusted for industry mix is also available. It deviates only slightly from the straight-time hourly earnings measures and suggests that interindustry shifts were relatively unimportant in influencing the data.

Lebergott series on full-time equivalent earnings was itself aggregated from nine individual industry series using constant employment weights. Because the payment of higher hourly rates for overtime and private

equivalent earnings fluctuate cyclically with hours of work in the industry; dividing full-time earnings by average hours of work of full-time employees should correct for this. However, the figure for average hours worked is presumably influenced by the proportion of people working part time, and so may overstate the cyclical movement in hours appropriate to correct the full-time equivalent earnings data. Hence the estimate in table 6 may understate the cyclical movement in this wage series during the prewar period. 
fringe benefits were probably rare in the prewar period, this series should be roughly comparable to the adjusted average hourly earnings index of the postwar period. ${ }^{17}$

The Rees series for manufacturing shown in table 6 is unweighted, but according to Rees a nine-industry weighted series from 1906 to 1914 seemed to make little difference in the cyclical behavior of the index.. ${ }^{18}$

For the postwar period, two wage series are used for the total private nonfarm economy. The first is the average hourly earnings series adjusted by the BLS for overtime in manufacturing and interindustry shifts. The second is an hourly compensation index, constructed along the lines suggested earlier by Gordon: it is the adjusted hourly earnings index multiplied by the ratio of compensation to wages and salaries in the national income accounts. ${ }^{19}$

The postwar estimates of wage flexibility in table 6 are based on the concepts underlying table 3 ; the change in both wages and nominal GNP was adjusted upward by 1.0 percentage point in the 1961-66 expansion. Subject to the major qualifications discussed above, the data show that for the nonfarm economy as a whole wage flexibility in the prewar period, which was not very great, fell to an even lower level in the postwar period.

Sachs' analysis of wage movements since the 1890 s also concludes that wage changes have become less flexible since the prewar years. ${ }^{20}$ But because he includes the years through 1976 with no adjustment for supply shocks, his measures of wage flexibility decline more than those shown above. Wage flexibility in manufacturing exceeded that for the overall economy in both periods; it, too, declined after the war. Wage flexibility was never large, but the combination of its smaller size and the lower amplitude of contractions in the postwar period produced a wage series that rose only slightly less in contractions than in expansions.

The growth of multiyear contracts in the union sector of the economy is one obvious reason for the changed behavior. Flanagan has found, for

17. See the Lebergott series in U.S. Bureau of the Census, Historical Statistics of the United States: Colonial Times to 1970 (U.S. Government Printing Office, 1975), p. 164; the Kendrick-BLS series is from Bureau of the Census, Long Term Economic Growth, 1860-1965 (GPO, 1966), pp. 192-93.

18. Albert Rees, "Patterns of Wages, Prices and Productivity," in Charles A. Myers, ed., Wages, Prices, Profits, and Productivity (American Assembly, Columbia University, 1959), pp. 11-35.

19. See Robert J. Gordon, "Inflation in Recession and Recovery," BPEA, 1:1971, pp. $115-16$.

20. Sachs, "The Changing Cyclical Behavior." 
Table 7. Cyclical Behavior of Real Wages, Peacetime Cycles, 1900-66

Percent per year

\begin{tabular}{|c|c|c|c|c|c|}
\hline \multirow[b]{2}{*}{ Period and measure } & \multicolumn{5}{|c|}{ Mean annual change } \\
\hline & $\begin{array}{l}\text { Private } \\
\text { nonfarm } \\
\text { deflator }\end{array}$ & $\begin{array}{l}\text { Consumer } \\
\text { price } \\
\text { index }\end{array}$ & $\begin{array}{l}\text { Adjusted } \\
\text { compensa- } \\
\text { tion index }{ }^{\mathrm{a}}\end{array}$ & $\begin{array}{c}\text { Compensa- } \\
\text { tion less } \\
\text { deflator }\end{array}$ & $\begin{array}{l}\text { Compensa- } \\
\text { tion less } \\
\text { consumer } \\
\text { price } \\
\text { index }\end{array}$ \\
\hline \multicolumn{6}{|l|}{ Prewar cycles } \\
\hline Expansions & 1.2 & 1.6 & 3.3 & 2.1 & 1.7 \\
\hline Contractions & -0.4 & -0.7 & 1.8 & 2.1 & 2.4 \\
\hline Change & 1.6 & 2.3 & 1.5 & 0.0 & $\overline{-0.7}$ \\
\hline \multicolumn{6}{|l|}{ Postwar cycles } \\
\hline Expansions & 2.8 & 2.0 & 4.8 & 2.1 & 2.9 \\
\hline Contractions & 1.4 & 1.6 & 4.0 & 2.7 & 2.4 \\
\hline Change & $\overline{1.4}$ & $\overline{0.4}$ & $\overline{0.8}$ & $\overline{-0.6}$ & $\overline{0.5}$ \\
\hline
\end{tabular}

Sources: Tables 3 and 6.

a. An adjusted Lebergott series was used for the prewar period; for the postwar period, a compensation index like that developed by Gordon. See Robert J. Gordon, "Inflation in Recession and Recovery," BPEA, $1: 1971$, pp. 115-16.

example, that union wages tended to be as responsive as nonunion wages to changes in economic conditions in the first year of a multiyear contract, but not in the remaining years. ${ }^{21}$

The finding that the flexibility of the nonfarm deflator did not decrease, while wage flexibility did, implies a somewhat changed cyclical behavior of real wages, as set forth in table 7. Measured against output prices (the nonfarm deflator) the reduced flexibility of nominal wages showed up as a tendency for real wages to rise faster in recessions relative to expansions than was the case in the prewar years. But because the prewar flexibility of farm and food prices disappeared in the postwar period, real wages measured against the total CPI tended to rise faster in expansions relative to contractions than they did before 1929. The data in table 7 also confirm the well-known finding that real wages measured in product prices show no systematic procyclical tendencies.

The fact that in both prewar and postwar periods real wages showed no major procyclical tendency has an important implication for sorting

21. Robert J. Flanagan, "Wage Interdependence in Unionized Labor Markets," $B P E A, 3: 1976$, pp. 651-54. 
out inflation theories. Under accelerationist theories, which are market clearing in expected prices, one of the two following alternatives must be invoked to account for expansions and contractions of output which persist over long periods of time: either there are "in-equilibrium" cyclical movements up and down the aggregate supply curve of labor resulting in procyclical swings of real wages, or the misperceptions, information lags, insularity, or whatever else it is that keeps perceived relative prices mistakenly high (or low) must somehow stubbornly persist over long periods of time in expansion after expansion (and similarly in contractions). The noncyclicality of the movement in real wages clearly rules out the first alternative.

In sum, the following findings have emerged about the flexibility of wages and prices relative to aggregate demand:

Final goods prices, measured either by the GNP deflator or the CPI, were never very flexible even in the prewar period, and that flexibility declined in the postwar period.

The decline in price flexibility in these indexes can be attributed to the behavior of farm and food prices. Government price-support policy in the postwar period largely eliminated the cyclical flexibility of farm prices. The nonfarm GNP deflator and the CPI excluding food exhibited a small and roughly stable response to changes in aggregate demand in both prewar and postwar periods.

Wage flexibility was small in the prewar period and became even smaller in the postwar period. Although nonfarm price flexibility was no smaller and wage flexibility declined, the absolute size of the decline in wage flexibility (from 0.15 to 0.11 for all nonfarm workers) was sufficiently smaller that it did not significantly alter the long-standing observation that there is little systematic cyclical movement in real wages.

\section{Implications for the Rational Expectations Model of the Economy}

The findings presented above about the flexibility of wages and prices relative to aggregate demand are particularly relevant for the implications of rational expectations and related theories that emphasize marketclearing price and wage behavior combined with misperceptions and information lags as an explanation of the response of inflation and output 
to changes in aggregate demand. In a rational expectations world, economic agents respond to observed price changes in two ways: to the extent they believe the price movements represent general inflation, there is a zero response of output-that is, a supply elasticity of zero. To the extent they believe the price movements represent "real" (that is, relative) changes, they respond along their various labor and output supply curves, with elasticities determined by the shape of those supply curves.

The observed elasticity of individual economic agents' supply response is, therefore, a weighted average: a zero elasticity multiplied by the proportion of the price change they believe to be general, plus an equilibrium supply curve elasticity multiplied by the proportion of the price change they believe to be real or relative. The observed aggregate supply curve is an aggregation of the individual weighted averages. ${ }^{22}$ According to the theory, therefore, the observed short-run aggregate supply curve is a weighted average of a zero elasticity and an elasticity that represents an equilibrium movement along the economy's underlying short-run supply elasticities. If, for example, agents on average tended to perceive half the observed price movements as general inflation, an observed supply elasticity of, say, 5 would imply the existence of an underlying elasticity along an equilibrium path of twice that amount, or 10 .

How big is the weighted output elasticity actually observed over the course of business cycles? The low value of the flexibility coefficient estimated above for both prewar and postwar periods (between 0.15 and 0.19 for nonfarm prices) implies a high value for the elasticity of the aggregate supply curve that simply cannot be accounted for in the rational expectations world. A $\lambda$ of this size implies a response of the inflation rate (relative to the perceived inflation norm) to output growth (relative to potential), given by $\lambda /(1-\lambda)$, of about 0.20 . The inverse of this re-

22. See the formulation by Robert E. Lucas, Jr., "Some International Evidence on Output-Inflation Tradeoffs," American Economic Review, vol. 63 (June 1973), pp. 326-34. If the response of an individual agent's output, $y_{t}(Z)$, to a perceived relative price is $y_{t}(Z)=\gamma\left(\bar{p}_{t}(Z)-p_{t}\right)+\delta y_{t-1}(Z)$, where $\bar{p}_{t}(Z)$ is the locally observed price whose relative component has a variance of $T^{2}$, and $p_{t}$ is the mean of the current perceived general price level with variance of $\sigma^{2}$, then the observed aggregate supply curve is $y_{t}=\theta \gamma\left(\bar{p}_{t}-p_{t}\right)+\delta \gamma_{t-1}$, where $\theta$ is the weighting variable, equal to $T^{2} /\left(T^{2}+\sigma^{2}\right)$. (Since the elasticity of response to perceived changes in general prices is zero, the $(1-\theta)$ weight for general price changes remains implicit in the above formulation.) 
sponse (5) defines the short-run elasticity of output on prices, that is, the elasticity of the short-run aggregate supply curve. If, at one extreme, all deviations of actual inflation from the norm are assumed to be initially perceived as relative price changes, then according to rational expectations doctrine the observed supply elasticity is also the underlying supply elasticity. If, however, some of the deviations are correctly interpreted as additional inflation, the underlying elasticity is higher than 5. But the implication that the underlying short-run elasticity along an equilibrium path traced out by the economy's supply curves is 5 or greater is extremely unrealistic. If the production function is Cobb-Douglas, the labor share of total income is designated as $b$, the elasticity of labor supply to perceived real wages is denoted as $\eta$, and the economy's combined short-run (capital-fixed) aggregate supply elasticity along an equilibrium path is given by ${ }^{23}$

$$
e_{c}=b \eta /[1+\eta(1-b)] .
$$

The value of the combined elasticity for selected values of $b$ and $\eta$ is shown below:

$\begin{array}{ccc}b & \eta & e_{c} \\ 0.67 & 0.2 & 0.13 \\ 0.67 & 0.5 & 0.29 \\ 0.67 & 1.0 & 0.50 \\ 0.75 & 2.0 & 1.0 \\ 0.75 & \infty & 3.0 \\ 0.86 & \infty & 6.1\end{array}$

If the production function is not completely "putty-putty," the short-run elasticity consistent with any given labor share, $b$ will be lower than that shown above.

If, for example, the elasticity of the labor supply is generously estimated at 0.50 and the labor share at 0.67 , the combined elasticity, $e_{c}$, is

23. If $L_{s}=\alpha W^{\eta}$, where $W$ is the wage rate, $M C$ is marginal cost, and $Q$ is output, then for capital fixed at $K_{0}$,

$$
\frac{\partial Q}{\partial M C} \cdot \frac{M C}{Q}=e_{c}=b \eta /[1+\eta(1-b)] .
$$

The (mainly insignificant) constants, appearing in the equations from which $\lambda$ was derived, were ignored as arising from price changes other than those generated by movements along the aggregate supply function. 
0.29 . To bring the combined elasticity up to 1.0 , a combination of unrealistically high assumptions (such as $b=0.75$ and $\eta=2.0$ ) must be employed. And to obtain a combined elasticity for equilibrium movements of 5 or higher, which is what the observed data imply in the rational expectations model, the economy must consist of an infinitely elastic supply of Gordon's "yeoman barbers." ${ }_{24}$

It is conceivable (although I believe highly unlikely) that the addition of inventory buffers, intertemporal substitution, or the like to a marketclearing model including misperceptions might be able to explain the high observed elasticity of output response to cyclical swings in aggregate demand. ${ }^{25}$ But in that case the high elasticity of output (and its mirror image, a low elasticity of prices) would be endemic to the system and would not be radically improved by a credible change in the policy regime. And I see no way that the observed elasticity can be explained as a special consequence of the nature of historical expectations about monetary or other macro policy, so as to argue that a different policy, in effect long enough to be credible, would have produced a lower elasticity. At one extreme it might be presumed that the historical policy regime and demand shocks were such that economic agents detected none of the above-norm inflation components in the individual price changes they experienced. In that case, the theory interprets the observed output response as an underlying elasticity of 5 . As one relaxes this extreme assumption in

24. Robert J. Gordon, "The Product Market and Macroeconomics: the Neglected Stepchild," paper presented at the Arthur M. Okun Memorial Conference, Columbia University, September 25-26, 1981.

25. The early Lucas model, "Expectations and the Neutrality of Money," with its emphasis on intertemporal substitutions, might be used to account for a high elasticity of labor supply during cyclical swings under two different expectational regimes. First, workers misperceive general wage increases as relative increases that, however, they expect to be temporary; hence they shift the temporal patterns of their labor input to the present, saving their leisure for later periods of low real wages. But for workers to hold such expectations in the face of consistent contrary experience that expansion gains in real wages are not subsequently wiped out in contraction would hardly be rational. Second, workers correctly perceive that part of their wage increase has a component of general inflation, but expect the price level to fall in the future, and hence supply more labor input currently so they can accumulate liquid assets and enjoy the subsequent real capital gains. This interpretation of the behavior of labor supply flies in the face of so many facts (such as the minuscule historical size of workers' liquid asset holdings, the lack of any basis for expecting price level declines in the postwar period, and the cyclical behavior of quit rates) that it cannot seriously be offered as an explanation for the large underlying elasticities of supply implied in rational expectations theory. 
the direction of more accurate inflation prediction, the implied underlying elasticity must be supposed, by the theory, to be an even more unrealistically large number. ${ }^{26}$

Models of the aggregate supply curve that emphasize price and wage stickiness and the existence of persistent disequilibriums and excess supplies-whatever their other difficulties-have no problem in accounting for the high observed elasticity of output relative to price. The observed movements do not imply a high elasticity of equilibrium movements along the economy's supply curves.

The evidence presented above that nonfarm price flexibility did not substantially change between the prewar and postwar years raises another doubt about the ability of a rational expectations model to explain the cyclical behavior of inflation.

The supposed effect of predictive or rational expectations about the future course of monetary policy on the rate of inflation depends upon a chain of relations. These are the effects of

(1) the past and current behavior and pronouncements of the monetary authorities on the expected future course of policy,

(2) the expected monetary policy on the expected course of aggregate demand,

(3) the expected course of aggregate demand on the expected future behavior of wages and prices,

(4) the (mean) expected behavior of future wages and prices on current wage and price decisions. ${ }^{27}$

Even in a world in which economic agents have come to believe (1) that monetary restraint will indeed be pursued in the face of political difficulties and (2) that this will be effective in reducing demand, their behavior will be quite different depending on their expectations about (3) the resulting split between output reduction and inflation reduction, and (4) the certainty with which they hold these views.

26. Perverse models of behavior are ruled out - that is, the theory cannot be reconciled with the observed elasticity by supposing that agents believe positive individually observed demand shocks to be systematically associated with negative aggregate demand shocks.

27. The concept of a relatively sticky inflation norm implies that the uncertainty with which expectations are held and the costs of reducing that uncertainty are large enough so that, within some limited range, changes in the expected value of inflation have only a muted impact on current behavior-in effect, they are ignored in favor of a backward-looking approach to price and wage setting. 
A monetary policy that credibly promises demand restraint will obviously yield more inflation reduction than one that does not. The history from which rational economic agents draw their predictions is not one in which inflation is immune to changes in aggregate demand. But the impact of a firmly expected demand reduction on current wage and price behavior will be much smaller if that demand reduction is generally forecasted to result principally in lower output rather than in lower prices. In the face of a firmly expected reduction in the demand for its industry's product, the management of a firm is much less likely to lower prices if it expects that other firms will not lower prices in the face of lower demand than if the opposite expectation is prevalent.

Proponents of rational expectations argue that the apparently sluggish inflation in mainline models derives from misleading reduced forms. The observed small coefficient that relates inflation to changes in aggregate demand arises from a structural system in which the response to an expected "permanent" drop in nominal demand is quite sizable, but has been masked in the aggregate data by the expectational consequences of an expected countercyclical monetary policy.

Hence if that expectational pattern were changed, economic agents, distinguishing the "true" reduced forms ${ }^{28}$ from the misleading historical macro relations, would respond with substantial price and wage flexibility. The principal reason that the management of the putative firm cited above did not reduce prices in the past when nominal demand fell was that it did not expect the decline to last and, more important, did not expect the competition to expect the decline to last. But if such an outcome had been predicted, management would have anticipated that the competition would expect the same thing, and all of them together would have lowered prices.

Although the evidence is not conclusive, the results of this paper point to quite a different inference. In the prewar period, when monetary policy was not systematically harnessed in favor of employment support and prolonged booms, the observed coefficients of final goods price inflation on changes in aggregate demand were not much different from what they were during 1950-66. They were small in both periods. Although the coefficient of wage flexibility has declined, it was never very large. The observed smallness of the coefficients, therefore, does not provide spurious information about price flexibility. In the past, when expectations about

28. The response of inflation to an expected permanent lowering of nominal demand. 
policy must have been quite different from what they are now, the coefficients were only modestly different from what they are now.

Thus far I have related cyclical changes in inflation solely to contemporaneous changes in aggregate demand, with no role either for the level of a disequilibrium variable or for the influence of recent changes in inflation on current wage and price behavior; in other words, I have ignored the possibilities of both Phillips curve and accelerationist effects. The following two sections deal with each of these influences in turn.

\section{The Level of Unemployment and the Gap}

Because the annual unemployment data for the earlier years of the century were indirectly estimated and are subject to large measurement errors, I have examined Phillips curve effects using the gap between actual and potential GNP as an alternative excess demand variable. In addition, an effort was made to convert Lebergott's raw unemployment data to a Perry weighted unemployment rate in order to make the unemployment measure at least roughly consistent over time as an index of labor market tightness. ${ }^{29}$

29. Two adjustments were made to the Lebergott data. First, his overall unemployment rate was converted to a nonagricultural unemployment rate. Farm unemployment was unlikely to be reported as such, and the farm sector accounted for about 40 percent of the labor force in 1900. As a consequence, the use of total labor force in the denominator of the unemployment rate substantially understates the rate of unemployment in earlier years compared to the postwar period. Thus

where $U R_{N A}=$ nonagricultural unemployment rate

$$
U R_{N A}=\left[U /\left(C L F-E_{A}\right)\right],
$$

$$
\begin{aligned}
U & =\text { total unemployment } \\
E_{A} & =\text { agricultural employment } \\
C L F & =\text { civilian labor force. }
\end{aligned}
$$

Second, the relation between the Perry weighted unemployment rate, $U R W$, and $U R_{N A}$ was fitted for the postwar period as follows:

$$
U R W=a_{0}+a_{1} U R_{N A}+a_{2} E M R 20(+),
$$

where $E M R 20(+)$ is the ratio of employment among males aged twenty and over to total employment. Decennial census data for 1900, 1910, 1920, 1930, and 1940 was interpolated annually to obtain prewar estimates of $E M R 20(+)$, which were used in combination with $U R_{N A}$ to estimate a prewar Perry weighted unemployment rate. The equation for $U R W$ above gave the following results:

$$
\begin{gathered}
U R W=-2.83+0.86 U R_{N A}+3.29 E M R 20(+) \\
(-7.1) \quad(48.2) \\
\bar{R}^{2}=0.987
\end{gathered}
$$

See the concept of a weighted unemployment rate in George L. Perry, "Changing Labor Markets and Inflation," BPEA, 3:1970, pp. 411-41. 
When the inverse of the weighted unemployment rate $(1 / U R W)$ was added to the equation, it took a small and only marginally significant coefficient, added very little to the explanatory power of the equation, but did lower the coefficient of the demand change variable. ${ }^{30}$ For example, compare the following results, fitted in the prewar and postwar cycles excluding the Great Depression, with their private nonfarm counterparts in table 4 :

or

$$
\begin{gathered}
\Delta p=0.16+0.15 \Delta q+1.8 \Delta(1 / U R W) \\
(0.6) \quad(3.0) \quad(0.5) \\
\bar{R}^{2}=0.64
\end{gathered}
$$

$$
\begin{gathered}
\left(p-p_{N}\right)=-0.14+0.13\left(q-q^{*}\right)-0.34(1 / \text { URW }) \\
(-0.2) \quad(2.5) \quad(-0.1) \\
\bar{R}^{2}=0.28 .
\end{gathered}
$$

The coefficients on $\Delta p / \Delta q$ and $\left(q-q^{*}\right)$ translate into a $\lambda_{y}$ of 0.13 and 0.12 for comparison with table 4 .

To look more closely at the reason for this failure of the Phillips curve variables to contribute substantially to the explanation of the cyclical sensitivity of inflation during peacetime cycles, a "standard" augmented Phillips curve equation was formulated and fit to annual data for the various periods and subperiods within the past eighty years. ${ }^{31}$ The basic

30. The fact that the observation units are cycle expansions and contractions means the unemployment data used in the regressions are averages of the unemployment rates in each of those units. Although this reduces the variance of the unemployment variable, substantial variance in the unemployment series still remains, as shown in the following tabulation of $U R W$ during expansions and contractions:

$\begin{array}{llll}1900-3 & 4.6 & 1924 & 4.9 \\ 1904 & 6.4 & 1925-26 & 1.5 \\ 1905-07 & 2.3 & 1927 & 3.1 \\ 1908 & 9.1 & 1928-29 & 3.0 \\ 1909-10 & 6.5 & 1949 & 5.2 \\ 1911 & 7.4 & 1950-53 & 2.4 \\ 1912-13 & 4.5 & 1954 & 4.7 \\ 1914 & 8.6 & 1955-57 & 3.4 \\ & & 1958 & 5.9\end{array}$

31. The unemployment inverse is averaged for years $t$ and $(t-1)$. The unemployment change variable, however, is not shifted backward; it represents the change between $t$ and $(t-1)$. Because the behavior of prices and of wages during the two wars and their immediate aftermath is quite different and also differed from peace- 
results are shown in table 8 , in which the dependent variable is the percent change in the private nonfarm deflator.

In the prewar years the level of unemployment appears to have had no effect on the rate of inflation. The coefficients on unemployment for various subperiods are small and insignificant. These results, however, are based on regressions that have dummy variables during the two war cycles when the unemployment rate was very low. When the World War I dummies are removed, the coefficient on 1/URW for the 1900-40 period rises to 7.1 (with a $t$-statistic of 1.2 ).$^{32}$ On balance, the evidence suggests that during prewar peacetime years when the unemployment rate seldom, and then only briefly, reached very low levels, Phillips curve effects do not appear. This result is not due to the poor measurement of annual unemployment before 1940 . For the $1902-40$ period an equation containing the gap between potential and actual GNP showed that the level of the gap had no significant influence on the inflation rate, but the change in the gap did.

Rather sizable Phillips curve effects do appear, however, in 1954-66 (and equally robustly in equations through 1969). And these effects hold up whether the unemployment variable is current or lagged, inverted or "straight."

The change in unemployment had a significant effect on inflation throughout the period up to 1966 , and this effect appeared to be quite stable when the estimates were split into various subperiods, although its value is a little lower in the 1954-66 subperiod than in earlier years. The

time cycles, dummy variables are entered for $1916-22(1.0$ in $1916-20 ;-1.0$ in 1921-22) and for 1941-47 (1.0 in 1941-45; - 1.0 in 1946-47). Dummies are also entered for the Korean War and Nixon price control periods. Finally, two adjustments were made to account for the direct and indirect effects of energy and food price increases: an estimate of the direct effect of domestic energy price increases on the private nonfarm deflator was subtracted from the dependent variable in 1974-76 and 1979-80. This direct energy effect was measured as the relative domestic energy price increase multiplied by current year quantities, all taken as a percent of private nonfarm GNP and entered three-fourths in the year of occurrence and one-fourth in subsequent years. For 1973-80 the impact of food and energy price changes on the change in the chain-weighted price index for personal consumption expenditures was also entered as a separate variable, but one-third was entered in the year of occurrence and two-thirds in the subsequent years. (For this latter variable see appendix A.)

32. In World War II the dummies take on a negative value, reflecting the effect of price and wage controls, and removal of the dummies does not contribute to a better estimate of the inflation impact of very low unemployment. 
Table 8. Standard Augmented Phillips Curve Equations for the Private Nonfarm Deflator, Selected Periods, 1902-80

\begin{tabular}{|c|c|c|c|c|c|}
\hline \multirow[b]{3}{*}{ Period } & \multirow{2}{*}{\multicolumn{3}{|c|}{ Independent variables }} & \multicolumn{2}{|c|}{ Summary statistic } \\
\hline & & & & \multirow[b]{2}{*}{$\bar{R}^{2}$} & \multirow{2}{*}{$\begin{array}{l}\text { Durbin- } \\
\text { Watson }\end{array}$} \\
\hline & $1 / U R W$ & $\triangle U R W$ & $p_{-1}$ & & \\
\hline $1902-80$ & $\begin{array}{l}1.56 \\
(0.8)\end{array}$ & $\begin{array}{l}-0.77 \\
(-6.7)\end{array}$ & $\begin{array}{c}0.26 \\
(3.8)\end{array}$ & 0.78 & 1.75 \\
\hline $1902-40$ & $\begin{array}{c}0.15 \\
(0.1)\end{array}$ & $\begin{array}{l}-0.57 \\
(-4.7)\end{array}$ & $\begin{array}{c}0.10 \\
(1.4)\end{array}$ & 0.87 & 2.23 \\
\hline $1902-54$ & $\begin{array}{l}1.20 \\
(0.5)\end{array}$ & $\begin{array}{l}-0.76 \\
(-5.5)\end{array}$ & $\begin{array}{c}0.23 \\
(2.9)\end{array}$ & 0.78 & 1.79 \\
\hline $1954-66$ & $\begin{array}{c}8.65 \\
(2.6)\end{array}$ & $\begin{array}{l}-0.57 \\
(-3.4)\end{array}$ & $\begin{array}{c}0.66 \\
(2.5)\end{array}$ & 0.63 & 2.00 \\
\hline $1965-80$ & $\begin{array}{c}1.11 \\
(0.2)\end{array}$ & $\begin{array}{c}0.14 \\
(0.2)\end{array}$ & $\begin{array}{c}0.51 \\
(2.1)\end{array}$ & 0.69 & 1.85 \\
\hline $1954-80$ & $\begin{array}{c}7.71 \\
(2.5)\end{array}$ & $\begin{array}{l}-0.49 \\
(-2.4)\end{array}$ & $\begin{array}{c}0.67 \\
(5.8)\end{array}$ & 0.84 & 2.10 \\
\hline $\begin{array}{l}\text { Peacetime cy } \\
\text { only }^{\mathrm{b}}\end{array}$ & $\begin{array}{c}-5.94 \\
(-2.0)\end{array}$ & $\begin{array}{l}-0.35 \\
(-2.8)\end{array}$ & $\begin{array}{c}0.09 \\
(0.65)\end{array}$ & 0.29 & 1.82 \\
\hline $\begin{array}{l}\text { Almon lags } \\
\text { pendent } \mathrm{v}\end{array}$ & & & & & \\
\hline $1954-66$ & $\begin{array}{l}12.24 \\
(4.2)\end{array}$ & $\begin{array}{l}-0.56 \\
(-3.9)\end{array}$ & $\begin{array}{c}0.91 \\
(3.1)\end{array}$ & 0.70 & $\ldots$ \\
\hline $1965-80$ & $\begin{array}{r}9.05 \\
(1.5)\end{array}$ & $\begin{array}{l}0.35 \\
(0.9)\end{array}$ & $\begin{array}{c}0.83 \\
(3.8)\end{array}$ & 0.82 & $\ldots$ \\
\hline $1954-80$ & $\begin{array}{l}11.38 \\
(4.3)\end{array}$ & $\begin{array}{l}-0.32 \\
(-1.9)\end{array}$ & $\begin{array}{c}0.79 \\
(7.5)\end{array}$ & 0.88 & $\ldots$ \\
\hline
\end{tabular}

Sources: Same as table 2 for the private nonfarm deflator; the Perry weighted unemployment rate is based on George L. Perry, "Changing Labor Markets and Inflation," BPEA, 3:1970, pp. 411-41.

a. The dependent variable is the percent change in the private nonfarm deflator. The variable $U R W$ denotes the Perry weighted unemployment rate; see note 29 for a description of the series. Not all coefficients are shown; see notes 31 and 32 for a description of the dummy variables. The numbers in parentheses are $t$-statistics.

b. These years are 1902-14, 1924-29, and 1950-66. The exclusion of the Korean War, during which inflation moved counter to Phillips curve predictions, does not significantly improve the fit of this equation. c. The lagged dependent variable is entered as an Almon lag with linearly declining weights constrained to be zero in the fifth year.

magnitude of the coefficient on the change in unemployment is roughly consistent with the $\lambda$ coefficients developed earlier, which relate inflation to the rate of change in nominal GNP. ${ }^{33}$ In the 1970s only the lagged de-

33. The Perry weighted unemployment rate changes by 0.86 point for each 1 point change in total unemployment (see note 23). With an Okun's law coefficient of 2.75 and the relation $\lambda=\beta /(1+\beta)$, one can calculate that a coefficient of 0.6 to 0.8 on $\Delta U R W$ is equivalent to a $\lambda$ of 0.16 to 0.20 , which is reasonably close to the values of $\lambda$ estimated above. 
pendent variable does well, as it picks up the longer-term speedup in inflation.

In the prewar period only the change in unemployment was relevant to the determination of inflation while both the change and the level of unemployment influenced the rate of inflation in the subsequent period. This suggests, I believe, certain conclusions about the micro analytics of the inflation process.

The association of the rate of inflation with the change in unemployment or output (relative to potential) that is found in both the cyclical and annual analysis implies a structure of wage and price behavior in which an expansion of output, relative to potential, leads to a one-time increase in the level of prices. As pointed out earlier, that behavior does not arise from a change in prices relative to wages - a classical movement of real wages along a downward sloping labor demand curve. The evidence presented in this paper confirms the findings of numerous other investigators that there is no systematic cyclical component to the movement of real wages. The behavior in question must stem from changes in nominal wages.

\section{Models of Wage Setting}

The model of wage determination set forth in Perry's 1980 paper explains an important part of the systematic cyclical behavior of inflation described here. ${ }^{34}$ In a period of Keynesian unemployment employers who want to increase the size of their work force substantially and quickly, faster than can be handled by screening the existing flow of applicants, are forced to increase wages more than that called for by the existing wage norm to expand the pool of new recruits and raise average quality. ${ }^{35}$ Summing across employers, this source of deviation in wage level is not

34. See George Perry, "Inflation in Theory and Practice," pp. 212-14.

35. Some large firms in concentrated industries that are subject to substantial fluctuations in demand tend to keep their wage levels higher than necessary to meet mean expected labor force requirements in order to ensure that they always have an available pool of qualified applicants to meet unexpected demands. See, for example, Charles L. Schultze, "Recent Inflation in the United States," in Study of Employment, Growth and Price Levels, Study Paper 1, 86 Cong. 1 sess. (GPO, 1959), pp. 1-137; and Alfred Kuhn, "Market Structures and Wage-Push Inflation," Industrial and Labor Relations Review, vol. 12 (January 1959), p. 249. This phenomenon tends to moderate and spread out the macro wage increase associated with an expansion of employment. 
a function of the level of unemployment but of the rate at which employment is changing relative to the labor force. The greater the number of employers needing to expand their work force and the faster they wish to expand it, the greater is the aggregate initial deviation in the wage level from that required to meet the norm.

The initial wage increase will lead to some further imitative wage rises, as other firms guard against attrition of their existing work force by matching the increase in the wage level. But so long as the fall in unemployment does not eliminate a Keynesian pool of willing applicants, and after the initiating firms have obtained their desired work force, there is no need for them to maintain the new wage differential. Maintenance of the old differential will keep their quit rates from rising and maintain their flow of new recruits at what it was originally. Indeed, to the extent that the imitative wage increases are less than the original ones, the initiating firms can, after their new work force has been obtained, raise wages by somewhat less than the norm until the original differentials have been restored. The overall response of the wage level to the change in unemployment is thereby muted.

In this process the flow of new recruits, out of the pool of recruits who would in any event have been satisfied to work at a given firm with its existing wage structure, is speeded up and channeled to those particular firms that are expanding through a temporary increase in relative wages. The macro consequence is a one-time rise in the wage level relative to the level dictated by the norm.

Okun models the same phenomenon somewhat differently. ${ }^{36}$ While employers, in the circumstances described above, do not need to maintain the newly opened wage differential, they observe the gradual spread of imitative wage movements of others, implicitly project those increases into the future, and conclude that they must offer a higher rate of increase in wages than in the past simply to maintain the old differential.

In other words, both the Perry and Okun models depict a labor market operating off the labor supply curve in which firms need to offer a wage increase relative to the norm in order to raise the flow of recruits to the firm but do not need to maintain a differentially higher wage to sustain the enlarged stock of employment once it has been achieved (again, so long as the Keynesian pool of unemployed has not been exhausted). In Perry's model, employers who first raised wages observe the imitative

36. Okun, Prices and Quantities, pp. 116-18. 
increase in wages elsewhere, and see it as a level adjustment. Their wage offers for the next period do not reflect a judgment that wages elsewhere will continue to rise at the recently observed rate. Okun's model assumes the opposite-the observed imitative rise is seen as a continuing higher rate of wage inflation, not as a one-time level adjustment. A Phillips curve results.

It is not surprising that the Perry model of the consequences of employment expansion (during periods of Keynesian unemployment) should best fit the prewar period while the Okun model would have some relevance in the postwar years. The difference between the two comes down to whether employers see imitative wage increases as a level adjustment or a rate-of-change adjustment. The early pages of this paper noted that, on average, prewar cyclical decelerations of aggregate demand were almost twice as large and twice as frequent as in the postwar period. Oftenrepeated previous experience suggested to employers in the prewar period that cyclical expansions of demand and output would last a short time and would soon be reversed in a large way. Postwar experience gradually drove home the opposite lesson. This is not a case of expectations about wages and prices driving inflation. Rather, it is a question of expectations about the likely variability of demand and output: to what extent, with respect to demand, do businessmen and workers believe the maxim, "what goes up must shortly come down"?

\section{Acceleration and Changes in the Norm}

There is a wide range of evidence that can be marshaled to indicate that inflation is not easily subject to accelerationist propensities of an adaptive kind. Over a wide intermediate range a change in inflation generated by a change in labor market tightness may occur without generating the continuing disappointments or serendipity that keeps expectations changing and inflation accelerating (or decelerating). Cyclical expansions in output and employment, for example, have not typically been kept going by an upward movement along labor supply curves. Expansions were not characterized by a continued acceleration in inflation as unemployment was held below the natural rate and price expectations were adjusted with a lag to actual experience.

The cyclical evidence was marshaled to ask two questions of the data: 
does inflation typically grow faster as expansion proceeds and unemployment stays at low levels, and does inflation typically continue to decline after a trough has been reached while unemployment and the GNP gap are still presumably above their "natural" levels?

A simple count was made to determine the extent to which inflation increased in each successive year of peacetime expansion (through 1964):

$\begin{array}{ccc}\begin{array}{c}\text { Year of } \\ \text { expansion }\end{array} & \begin{array}{c}\text { Number of } \\ \text { expansions }\end{array} & \begin{array}{c}\text { Number of cases } \\ \text { in which inflation } \\ \text { increased }\end{array} \\ 1 & 12 & 9 \\ 2 & 11 & 6 \\ 3 & 6 & 2 \\ 4 & 3 & 1\end{array}$

Thus in nine out of twelve peacetime cycles inflation rose during the first year of expansion. There were eleven cycles that lasted two years or more; in only five of those cycles did inflation continue to rise. In the third year of the six expansions that lasted three years or more inflation increased in only two cases. ${ }^{3 \tau}$ There was, in other words, no tendency for inflation to accelerate in the later years of cycle expansions.

Table 9 presents the same basic data in another form so that price behavior in each expansion can easily be contrasted with the behavior of unemployment. (The table excludes depression years.) The early years of a recovery were as likely as the later years to have a relatively large increase in inflation. In peacetime expansions before 1966 there was no tendency for inflation to accelerate as unemployment and the gap between actual and potential GNP narrowed.

On the other hand, in the prewar period not one of the expansions lasted past the third year. In the 1905-07 expansion, inflation did move up relatively strongly as the unemployment rate and the gap fell to unusually low levels. But the severe recession following the panic of 1907 nipped this in the bud-nonfarm GNP in real terms fell by more than 10 percent and in nominal terms by 11 percent in 1908. In the longer expansion of 1950-53, unemployment and the gap were pushed to very low levels. But inflation decelerated in the last two years of the boom. A number of very special elements characterized this period (including the collapse of a wildly misplaced inventory speculation in 1950 and the im-

37. Inflation was measured by the nonfarm deflator. Differences in the inflation rate of 0.3 percentage point or less were counted as "no change." 
Table 9. Behavior of Inflation and Unemployment during Peacetime Expansions, 1901-69

Percent

\begin{tabular}{|c|c|c|c|c|c|c|c|c|}
\hline \multirow[b]{3}{*}{ Year or period } & \multirow{2}{*}{\multicolumn{4}{|c|}{$\begin{array}{c}\text { Deviation of } \\
\text { inflation from the norm }\end{array}$}} & \multirow{2}{*}{\multicolumn{4}{|c|}{$\begin{array}{c}\text { Perry weighted } \\
\text { unemployment rate } \\
\text { Year of expansion }\end{array}$}} \\
\hline & & & & & & & & \\
\hline & First & Second & Third & Fourth & First & Second & Third & Fourth \\
\hline \multicolumn{9}{|c|}{ First year of expansion } \\
\hline 1901 & -4.4 & 0.9 & 0.9 & $\ldots$ & 5.0 & 4.3 & 4.5 & $\ldots$ \\
\hline 1905 & 1.5 & 1.2 & 1.7 & $\ldots$ & 4.9 & 1.7 & 3.0 & $\ldots$ \\
\hline 1909 & 0.2 & 1.4 & $\ldots$ & $\ldots$ & 5.6 & 6.4 & $\ldots$ & $\cdots$ \\
\hline 1912 & 2.5 & -1.3 & $\ldots$ & $\ldots$ & 4.9 & 4.5 & $\ldots$ & $\ldots$ \\
\hline 1925 & 0.8 & -1.5 & $\ldots$ & $\ldots$ & 3.0 & 1.5 & $\ldots$ & $\ldots$ \\
\hline 1928 & 0.6 & 0.2 & $\ldots$ & $\ldots$ & 3.1 & 4.0 & 3.0 & $\ldots$ \\
\hline 1950 & -0.7 & 4.1 & -0.5 & -0.3 & 4.4 & 2.5 & 2.3 & 2.3 \\
\hline 1955 & -0.4 & 0.8 & 1.0 & $\ldots$ & 3.6 & 3.3 & 3.5 & $\ldots$ \\
\hline 1961 & -0.8 & 0.1 & -0.2 & -0.2 & 5.6 & 4.5 & 4.4 & 3.9 \\
\hline \multicolumn{9}{|c|}{ Additional years ${ }^{b}$} \\
\hline 1965 & \multicolumn{4}{|c|}{0.1} & \multicolumn{4}{|c|}{3.2} \\
\hline 1966 & \multicolumn{4}{|c|}{1.3} & \multicolumn{4}{|c|}{2.6} \\
\hline 1967 & \multicolumn{4}{|c|}{1.7} & \multicolumn{4}{|c|}{2.7} \\
\hline 1968 & \multicolumn{4}{|c|}{2.5} & \multicolumn{4}{|c|}{2.4} \\
\hline 1969 & \multicolumn{4}{|c|}{3.3} & \multicolumn{4}{|c|}{2.3} \\
\hline
\end{tabular}

Source: Same as table 8.

a. Inflation is measured as changes in the private nonfarm GNP deflator.

b. Deviation measured from a constant 1.2 percent inflation norm in all years.

plementation of wage and price controls in 1951). It has usually been treated as a special case..$^{38}$

The 1961-69 expansion stands out starkly. It is more than double the length of any previous expansion, and during its latter half unemployment was consistently held at exceedingly low levels, well below the level at which Keynesian unemployment was exhausted. After 1965, inflation accelerated steadily. And the acceleration was not associated with a

38. See John Lewis, "The Lull that Came to Stay," Journal of Political Economy, vol. 63 (February 1955), pp. 1-19; Bert G. Hickman, "The Korean War and the United States Economic Activity," Occasional Paper 49 (National Bureau of Economic Research, 1955); and Perry, "Changing Labor Markets and Inflations," p. 421 . 
speedup in the rate of change in aggregate demand. In 1960-64, 80 percent of the expansion of nominal GNP found its way into higher output and 20 percent into higher prices. In 1965-69 the ratio dropped to 60 and 40 percent, respectively.

From table 9, therefore, one can infer that inflation has consistently been quite resistant to accelerationist tendencies or norm shifts, even when unemployment and the GNP were pushed to fairly low levels, so long as those levels were not maintained over a substantial length of time. At the same time, the 1966-69 experience strongly suggests that maintenance of high demand pressures and inflation rates well above the norm for a sustained period does set in motion acceleration or norm shifting. This period and its norm shift are discussed further below.

Table 9 is based on annual data and conceivably could give misleading signals about the acceleration or deceleration of inflation near cyclical turning points. An examination of monthly CPI and WPI data can help resolve this problem.

If all the world were a wheat pit, with markets characterized by flexprices that cleared immediately in response to disturbances, and if movements in nominal demand were unpredicted by traders, then except for supply shocks, inflation would rise or fall as nominal GNP accelerated or decelerated. But most markets do not instantaneously clear, and serially correlated movements in output and employment regularly occur. Each of the various models of the inflationary process implies a different cyclical timing for the inflation that results.

Accelerationist models - with adaptive expectations and relatively short lags in the expectations function-require that prices continue to accelerate (decelerate) so long as the actual rate of unemployment or the GNP gap is below (above) its natural rate. As long as the cycle trough is low enough to keep unemployment above the natural rate well into the recovery, inflation should continue to decelerate after the trough. (If prices were falling during the contractions they would not begin to rise again immediately after the trough.) The mirror image holds for a rise in inflation at the cycle peak. Phillips curve models should have inflation moving simultaneously with the cycle, rising and falling with the level of unemployment or the GNP gap. In the modified Keynesian model presented earlier, the deviation of inflation from its "norm" should move with the rate of change of GNP; cyclical timing of peaks and troughs in inflation should depend on the specific course of nominal GNP during the cycle. 
Because none of the models is "pure" and flexprices do account for some fraction of overall price movements, especially in the WPI, one cannot sort out inflation theories simply on the basis of cyclical timing. But an examination of the cyclical behavior of monthly wholesale and retail prices can provide some help in determining the presence or lack of accelerationist tendencies.

Table 10 shows the timing of peaks and troughs in the level and rate of change in wholesale industrial prices and the rate of change of consumer prices relative to the peaks and troughs of peacetime business cycles through $1966 .{ }^{39}$ The data shown are centered six-month moving averages to smooth erratic monthly fluctuations.

With a few exceptions, mainly in the 1920 s when there was a downtrend in wholesale prices, the level of wholesale prices reached peaks and troughs roughly coincident with peaks and troughs in the level of economic activity. Both wholesale and consumer price inflation rates tended to reach peaks and troughs well before cycle peaks and troughs. On both counts this behavior is at least roughly consistent with the rate-of-change formulation set forth earlier in this paper. Generally, but not universally, the periods of greatest accelerations and decelerations of aggregate demand precede cycle peaks and troughs. The timing of price behavior is clearly inconsistent with an accelerationist model.

While the foregoing cyclical analysis suggests that an absence of accelerationist tendencies over the range of movements in aggregate demand characterized peacetime cycles up through the mid-1960s, how about the econometric evidence from the coefficients on the lagged dependent variable in table 8 ? The coefficient on $p_{-1}$, which was quite low in the periods before 1954, suddenly jumped to 0.66 in 1954-66. A longer-term (four-year) Almon lag on the dependent variable shows a sum of coefficients approaching 1.0 for that period. Gordon's recent papers display a similar pattern-a low or nonexistent value for the prewar years and a (long-lagged) sum of coefficients approaching 1 beginning in the 1950s.

Does this provide evidence that experience with employment-supporting demand policy in the postwar period created an environment in which expected inflation, or the norm, began to adjust continuously to actual inflation experience? I think the answer is no.

39. Because the level of CPI often did not fall during a contraction, only the timing of its rate of change is shown in the table. 
Table 10. Timing of Cyclical Movements in the Wholesale Price Index and Consumer Price Index, Selected Years, 1900-61 ${ }^{\mathrm{a}}$

Number of months

\begin{tabular}{|c|c|c|c|}
\hline \multirow[b]{3}{*}{ Year and measure } & \multicolumn{3}{|c|}{$\begin{array}{l}\text { Months preceding }(+) \text { or trailing }(-) \\
\text { business cycle peaks or troughs }\end{array}$} \\
\hline & \multicolumn{2}{|c|}{ Wholesale price index } & \multirow{2}{*}{$\begin{array}{c}\begin{array}{c}\text { Consumer } \\
\text { price index }\end{array} \\
\begin{array}{l}\text { Rate of } \\
\text { change }\end{array}\end{array}$} \\
\hline & Level & $\begin{array}{l}\text { Rate of } \\
\text { change }\end{array}$ & \\
\hline \multicolumn{4}{|l|}{ Cycle troughs } \\
\hline 1900 & -1 & +4 & $\ldots$ \\
\hline 1904 & -1 & +15 & $\ldots$ \\
\hline 1908 & +2 & +7 & $\ldots$ \\
\hline 1912 & +1 & +16 & $\ldots$ \\
\hline 1914 & -1 & +19 & $\ldots$ \\
\hline 1921 & -7 & +6 & +4 \\
\hline 1924 & -2 & +11 & +3 \\
\hline 1927 & -3 & +9 & +1 \\
\hline 1933 & -0 & +23 & +12 \\
\hline 1938 & -12 & +5 & +5 \\
\hline 1949 & 0 & +6 & +8 \\
\hline 1954 & 0 & +5 & +1 \\
\hline 1958 & -1 & 0 & +6 \\
\hline $1961^{b}$ & $\ldots$ & +6 & +1 \\
\hline \multicolumn{4}{|l|}{ Cycle peaks } \\
\hline 1902 & -4 & +1 & $\ldots$ \\
\hline 1907 & 0 & +6 & $\ldots$ \\
\hline 1910 & -4 & +7 & $\ldots$ \\
\hline 1913 & -2 & +10 & $\ldots$ \\
\hline 1923 & +1 & +10 & 0 \\
\hline 1926 & +12 & +22 & +13 \\
\hline 1929 & +9 & +13 & 0 \\
\hline 1937 & -2 & +3 & +45 \\
\hline $1948^{\mathrm{c}}$ & 0 & +12 & $\ldots$ \\
\hline $1953^{d}$ & -3 & +2 & $\ldots$ \\
\hline 1957 & -3 & +22 & +3 \\
\hline 1960 & +2 & +18 & +8 \\
\hline
\end{tabular}

Sources: Same as table 5 .

a. Data are centered six-month moving averages. A plus $(+)$ sign indicates that the price peak or trough came earlier than the business cycle peak or trough by the number of months shown for the year.

b. From 1959 through 1963 the six-month average of the wholesale price index moved within the narrow range of 94.6 to 95.6 .

c. Peak CPI change occurred in September $1946(+26)$ but several lesser peaks followed.

d. Peak CPI change occurred in March $1951(+29)$, but several lesser peaks followed. 
As was noted above, the variance of inflation in 1954-66 was quite small compared to preceding and subsequent periods, as was the variance in nominal aggregate demand, unemployment, and output. The average level of inflation from 1961 through 1966, however, was modestly lower than it was in 1954-60, and this could not be explained by a higher average level of unemployment or a pattern of changes in unemployment. Anything that explains the fact of that lower average will account for much of the variance in inflation during this period. This paper has modeled the phenomenon as a norm shift (a shift from a 2.5 percent norm to a 1.5 percent norm, occurring in 1961), most probably resulting from the experience of two back-to-back recessions separated only by an aborted recovery. It is this phenomenon that is picked up by the coefficient on the lagged dependent variable. Thus if the dependent variable is defined as $\Pi_{t}=\left(p_{t}-p_{N}\right)$, and the equation for 1954-66 refit, the coefficient on $\Pi_{t-1}$ drops to a range of 0.14 to 0.36 (depending on whether the norm is shifted in 1961 or 1960 with $\bar{R}^{2}$ of 0.72 and 0.77 , respectively).

Such a test does not itself establish the superiority of the "sticky" norm model over a continuous adjustment approach. Indeed, it hinges on the presupposition that the norm did in fact change because of economic conditions. But what it does show is that the high value of the coefficient on the lagged dependent variable results from a very specific phenomenon: the average level of inflation in the second half of the period was lower than in the first half, and this could not be explained by the disequilibrium variables in the equation $(1 / U R W$ and $\triangle U R W)$. This phenomenon is clearly not evidence for an adaptive expectations, natural rate model or for a postwar shift toward accelerationist propensities brought about by employment-supporting aggregate demand policy.

Based on evidence of various kinds, therefore, the behavior of inflation in peacetime cycles suggests that economic agents do not respond as accelerationist theory requires: persistent movements in output and employment during periods that characterized most of business-cycle history since 1900 cannot be linked to persistent accelerations or decelerations in inflation. The greater part of these cyclical movements did not take place along or in the neighborhood of labor supply curves, requiring continual and self-defeating efforts to change real wages, relative wages, or both. And, in the formulation set forth in this paper, significant changes in the inflation norm did not occur easily or quickly. 
Table 11. Price and Wage Flexibility in Major Wars and Their Aftermath

Percent change per year or ratio

\begin{tabular}{|c|c|c|c|c|c|}
\hline Period & $\begin{array}{c}\text { Nominal } \\
G N P^{\mathrm{a}} \\
(y)\end{array}$ & $\begin{array}{c}G N P \\
\text { deflator }^{\mathrm{a}} \\
(p)\end{array}$ & $\begin{array}{c}\text { Ratios } \\
p / y \text { or } \Delta p / \Delta y\end{array}$ & $\begin{array}{c}\text { Wholesale } \\
\text { price } \\
\text { index }\end{array}$ & $\begin{array}{c}\text { Economy- } \\
\text { wide } \\
\text { wages }^{\mathrm{b}}\end{array}$ \\
\hline \multicolumn{6}{|l|}{ World War I } \\
\hline $1915-20$ & 18.0 & 15.6 & 0.87 & 17.4 & 16.7 \\
\hline $1920-22$ & -10.0 & -13.0 & 1.30 & -20.9 & -4.4 \\
\hline Deceleration $(\Delta)$ & -28.0 & -28.6 & 1.02 & $\overline{-38.3}$ & $\overline{-21.1}$ \\
\hline $1915-22$ & 9.2 & 6.6 & $\ldots$ & 4.9 & 10.3 \\
\hline \multicolumn{6}{|l|}{ World War II } \\
\hline $1941-48$ & 11.0 & 7.8 & 0.71 & 9.1 & 11.0 \\
\hline $1948-49$ & -0.5 & -1.0 & $\underline{2.00}$ & -5.0 & 3.3 \\
\hline Deceleration $(\Delta)$ & -11.5 & -8.8 & 0.77 & -14.1 & -7.7 \\
\hline $1941-49$ & 9.5 & 6.7 & $\ldots$ & 7.2 & 10.3 \\
\hline
\end{tabular}

Sources: GNP series-same as table 1; wholesale price index-Bureau of Labor Statistics; wage seriessame as table 6 .

a. Total GNP. Use of private nonfarm GNP makes little difference; the private nonfarm deceleration ratio in World War I is 1.02 instead of 1.03 and in World War II, 0.65 instead of 0.77 .

b. Lebergott series as described in table 6 .

\section{War and Postwar Adjustments}

It was pointed out above that during both world wars and the recessions that immediately followed (1921 and 1949) inflation behaved quite differently relative to changes in aggregate demand than it did during the peacetime cycles. Just how different this behavior was is set forth in table 11.

Although there were some sharp differences in economic developments and economic policy, the two periods shared a number of common characteristics. In both periods the wartime boom was followed immediately by a noncyclical drop in output (1946 and 1919-20), as war plants were converted to peacetime uses. Inflation continued, and indeed accelerated, during these reconversion periods. The subsequent booms ended in recessions-very steep in 1921, mild in 1949.

During both these periods price increases absorbed a large part of the huge rise in nominal GNP. This is not surprising because in both periods unemployment and the GNP gap were reduced to very low disequilibrium levels. (For example, the Perry weighted unemployment rate fell to 1-1/2 percent in 1918 and in 1943-45.) While Phillips curve reactions were weak in the range of unemployment and the gap that typically char- 
acterized peacetime cycles, they became powerful in the conditions that dominated both war periods. The earlier supply curve equation, from which a relatively small " $\lambda$ " was derived, is not valid under these conditions.

Perhaps more surprising is the fact that the deceleration coefficients, $(\Delta p / \Delta y)$, were so large in the subsequent recessions. Prices absorbed all, or more than all, of the recession declines in nominal GNP. Wages also decelerated very rapidly in both postwar recessions. ${ }^{40}$

The rapid and unusual fall in inflation in the recessions immediately following the two wars is, I think, instructive. It is, on the one hand, consistent with a rational expectations view of the world. Precisely because both wars were, and more importantly, were seen to be, unique events, neither the inflation they generated nor the monetary policies that accompanied them were extrapolated into the future. The first sign of major weakness in economic activity led to a collapse of price expectations. Alternatively, the wartime evidence can also support an Okun-Perry nonaccelerationist model. Again, because the wartime developments were seen as unique events, they did not give rise to a major increase in the inflation norm. Firms did continue to bid up wages rapidly and competitively during the war in an attempt to hire more workers in a labor market where Keynesian unemployment had completely disappeared. And even though labor markets eased somewhat when the war ended, they remained relatively tight into the immediate postwar boom. But the very high inflation rates did not get built into the "norm" that underlay implicit wage contracts. Sharp reductions in the rate of wage increases in the recessions of 1921 and 1949 did not violate those implicit wage contracts.

\section{The Past Fifteen Years}

Conflicting interpretations of the transition from the felicitous and apparently stable trade-off of the 1960 s to a decade of simultaneously higher inflation and unemployment have been debated on a number of occasions in the pages of Brookings Papers. On the most recent occasion the discussion was focused on George Perry's 1980 inflation article and

40. It is interesting that real wages rose sharply over both wartime cycles taken as a whole. 
the competing equations and interpretations of Robert Gordon. I do not attempt to provide an alternative econometric solution here to the puzzle of the transition. In this section, however, major events are reviewed that had an impact on inflation during the period since 1965, and contrasts are made with the previous history of inflation in the United States. The conclusion is that the worsened inflation and unemployment of recent years did not result from a series of policy mistakes and exogenous shocks impinging on an economic structure that is fundamentally accelerationist and inflation prone. Rather, a historically unparalleled series of inflationary events, including economic policy "mistakes," impinged on an economic structure that was relatively inflation-resistant. These developments were so large as to raise sharply, in several episodes, what had hitherto been a small and rather sticky norm. Quite possibly, but not certainly, a decade of relatively high inflation may have also changed the ease with which actual inflation now gets translated into a new norm.

Most researchers treat the turn of the decade and the failure of inflation to slow during the 1970-71 recession as the beginning of the transition. In fact, however, it was the last half of the 1960s that broke with the past (in terms of events, not economic structure). I noted earlier how unique the expansion of the 1960s was. By mid-1965 the expansion was already longer than any other in twentieth century history. The expansion was then extended yet another four years. As shown in table 9, the Perry weighted unemployment rate was pushed to low levels not experienced since the Korean War and held there for four consecutive years. ${ }^{41}$ Deviations of inflation from a very modest norm, which had been remarkably small during the first five years of the expansion, began to grow larger each year in the last half of the expansion.

Throughout this paper I have stressed evidence that large shifts in the norm do not occur easily. But the norm is clearly not immune to large and persistent deviations of actual inflation from it. Unlike the situation in the First and Second World Wars, every effort was made in the late 1960 s to convince the country that a peacetime economic situation existed. There was no tax increase until very late in the game; there were no controls or rationing, no mobilization of the reserves or of industry, and the country simultaneously embarked on the ambitious creation of a

41. Moreover, the labor market tightness represented by a given level of Perry weighted unemployment was probably greater than in most previous periods. 
Table 12. Illustrative Measures of Pressure for Norm Shifting, Selected Periods, 1900-69a

Percentage points

\begin{tabular}{cccc}
\hline & Deviation of inflation from the norm & $\begin{array}{c}\text { Change in GNP less } \\
\text { change in potential } \\
\text { during subsequent } \\
\text { contraction }\end{array}$ \\
\cline { 2 - 4 } & Additive & $\begin{array}{c}\text { Multiplied by } \\
\text { duration }\end{array}$ & -6 \\
$1900-03$ & $-3(2)^{\mathrm{b}}$ & $-3(3)^{\mathrm{b}}$ & -14 \\
$1904-07$ & 4 & 8 & 0 \\
$1908-10$ & 2 & 2 & -10 \\
$1911-13$ & 1 & 1 & -4 \\
$1924-26$ & -1 & -1 & -45 \\
$1927-29$ & 1 & 1 & -5 \\
$1949-53$ & 3 & 2 & -5 \\
$1954-57$ & 1 & 2 & -4 \\
$1960-69$ & 9 & 19 & \\
\hline
\end{tabular}

Source: Same as table 1.

a. Based on private nonfarm GNP. See text for an explanation of the series.

b. In 1901, the first year of expansion, the deviation of inflation from the norm was -4.4 percent. The numbers in parentheses give the results when that year is excluded from the calculations.

c. Deviations were mainly small negative values through 1964 . The calculations shown in the first and second columns begin with 1965 as the first year.

"Great Society." As inflation began to rise, there was no effort to blame it on an abnormal wartime situation or to take wartime steps to deal with it.

The persistence of wage and price norms-or, if you will, the lack of accelerationist tendencies-over the range of experience in previous peacetime cycles suggests that the learning process by which old norms and rules of thumb are abandoned for new ones depends on both the magnitude and the duration of the disequilibria that give rise to a deviation of actual inflation from the norm. Several crude indexes of the magnitude of relative pressures leading to a norm shift are presented in table 12. The quantification is not meant to suggest that there is some continuous function that can be discovered or that the forces making for a norm shift all arise out of past inflation experience. Rather, it is an attempt to convey how uniquely large the size and duration of the inflation deviations were during the late 1960s.

The first column of the table simply sums the deviations of inflation from the then-existing norm during peacetime cyclical expansions. By this measure of "norm shift pressure" the 1961-69 expansion generated pressure anywhere from three to nine times as large as any other peace- 
time expansion except one. And even that one, 1904-07, generated deviations only half as large. Moreover, the 1904-07 expansion was immediately followed by an exceedingly sharp decline in GNP relative to potential (see the third column) while the 1960-69 expansion was succeeded by a small contraction.

The second column attempts to take into account the persistence of disequilibria as an important aspect of a learning reinforcement process by which old norms are converted to new ones. To form the index for the second column each year's deviation of inflation from the norm was multiplied by the number of years that the deviation had persisted during the cyclical expansion, and the results were summed. Thus, a deviation series 1, 1, 2 for three years of expansion would be converted to 1, 2, 4 and summed for an index of 7. Again, on this measure, 1961-69 was highly unusual in terms of the pressures for norm change that were generated. Theory offers no warrant for the particular form of the index in the second column. But the concept of reinforcement, as a means by which the experience of persistent disequilibria break through existing norms, does suggest the existence of an interaction between the magnitude and the persistence of disequilibria and inflation deviations.

Perry's 1980 equations suggest an upward shift of 4-1/2 percent in the wage norm for the 1970 s as a whole. It is unlikely that there was a single one-time shift. The decade of the 1970s not only opened as the norm was shifting upward; it witnessed several other events of sufficiently large magnitude to have led, in all probability, to additional norm shifts. Table 13 provides several relevant measures of the magnitude of supply shocks from the farm and energy sectors. The effect of energy price rises on the chain-weighted price index for personal consumption expenditure, shown in the final column of table 13 , takes into account both the effect on energy products bought directly by consumers and the indirect effect through energy cost increases paid by business firms and passed on to consumers in the prices of nonenergy products. (See appendix A for a summary of how this measure was constructed.)

If the norm is resistant to quick changes, the normal procyclical fluctuations in farm prices such as those that occurred in the prewar period should not affect it. Only once before during the period since 1900 did a sharp rise in real farm prices suggest the existence of a major supply shock. That happened in the 1908-10 expansion and was immediately followed by a sharp drop in real farm prices in 1911. The 1972-73 rise 
Table 13. Measures of Farm and Energy Price Shocks, Selected Years, 1973-80a Percentage points

\begin{tabular}{|c|c|c|c|c|c|c|}
\hline \multirow[b]{2}{*}{ Year } & \multicolumn{3}{|c|}{ Direct effects on GNP deflator } & \multicolumn{3}{|c|}{$\begin{array}{l}\text { Effects on chain-weighted price index } \\
\text { of personal consumption expenditure }\end{array}$} \\
\hline & Total & Farm & Energy & Total & Food & Energy \\
\hline 1973 & 1.3 & 1.3 & b & 2.4 & 2.0 & 0.5 \\
\hline 1974 & 0.3 & -0.5 & 0.8 & 3.9 & 1.5 & 2.4 \\
\hline 1975 & 0.0 & -0.4 & 0.4 & 1.1 & 0.2 & 0.9 \\
\hline 1978 & 0.3 & 0.3 & b & 0.8 & 0.7 & 0.1 \\
\hline 1979 & 0.7 & 0.2 & 0.5 & 2.8 & 0.8 & 2.1 \\
\hline 1980 & 0.7 & -0.4 & 1.1 & 3.3 & 0.2 & 3.2 \\
\hline
\end{tabular}

Source: Calculations by the author based on national income and product accounts.

a. The direct effects of farm prices on the GNP deflator are measured as the contribution of changes in the farm sector deflator to the overall GNP deflator. The direct energy effect on the GNP deflator is calculated from changes in the average price of domestically produced oil, natural gas, and coal. Assuming a dollar-and-cents pass-through, three-fourths of the contribution is entered in the year of occurrence and the remainder in the subsequent year. The direct impact of food and energy prices on the personal consumption expenditure deflator is the sum of the increase in consumer food and energy prices multiplied by their relative importance in the fixed weight deflator plus an estimate of the increased cost of energy incorporated in other consumer goods. The pass-through of indirect effects is accomplished in two stages; two-thirds in the year of occurrence, one-third in subsequent years.

b. Not calculated.

in real food prices, however, was not fully reversed in immediately subsequent years.

Before 1973 there is no evidence of any upward shift in real energy prices. Furthermore, an admittedly brief review of wholesale price indexes does not suggest the previous existence of supply shocks in other industries at all comparable to the oil shocks of 1974 and 1979-80. ${ }^{42}$ The 1970s are highly unique in the magnitude of the supply shocks that occurred. Given an aggregate demand policy that, over time, at least accommodated the direct impact of the shocks, the economy had to absorb a total increase of almost 14 percent in the price level in a relatively short period of time, and this estimate does not allow for any increase in the norm arising from the supply shocks.

In addition to supply shocks from food and energy, the economy also had to adjust to a major slowdown in productivity growth. ${ }^{43}$ If, as is

42. A more thorough review of the data and the literature is undoubtedly warranted. The decline in real raw materials prices from 1955 to 1964 may, for example, have contributed to the modest shift downward in the norm that apparently occurred between the 1950s and 1960s.

43. While it is possible that part of the productivity slowdown was itself due to the higher and more variable inflation, the consequences remained the same as if it were exogenous. 
generally agreed, most prices tend to be set in relation to standard unit labor costs, a perceived one-time reduction in the productivity level will lead to an increase in the level of the aggregate supply curve unless the level of the nominal wage norm is shifted downward. The same conclusion, in first-difference form, is applicable to a perceived slowdown in the productivity growth rate. But there is no reason to posit a downward shift in the nominal wage norm in response to a productivity decline if the price-raising effects of that decline are accommodated by a rise in nominal aggregate demand. If the typical sectoral supply shock can be kept from affecting the norm, its effect on inflation will be temporary. But a long-term slowdown in productivity growth, even if kept out of the norm, will raise the rate of price inflation permanently; and if some of the increased inflation gets into the norm, the effect will be still larger.

There is disagreement among analysts about the precise timing of the decline in the growth trend of productivity. In the last three years, however, productivity growth in the private nonfarm economy has been virtually zero. If, on the strength of recent experience, businessmen in the aggregate are now pricing on the basis of a zero to 1 percent a year productivity gain, the loss of productivity growth over the past decade has amounted to an increase of about $1-1 / 2$ to 2 percentage points in the annual inflation embedded in the aggregate supply curve.

A final, and very tentatively suggested, source of upward pressure on the aggregate supply curve in the past decade may have been the behavior of union wages. While a number of authors have noted that during the 1960s union wages tended to rise less than nonunion wages, ${ }^{44}$ the reversal of the process in the 1970s has far more than made up for it. The average annual effective increase in wages in union contract settlements involving more than 1,000 workers was 8.4 percent in the 1970 s versus an adjusted wage increase of 7.6 percent for all workers. The relative gains of a small number of large unions in industries that are concentrated, regulated, or benefiting from high energy prices have been even greater. Average straight-time hourly earnings in nine major industries (steel, automobile, aluminum, canning, trucking, rail, petroleum refining, coal mining, and communications) rose from 19 percent above the average for all manufacturing in 1967 to 42 percent above it in 1980 .

44. Perry, "Inflation in Theory and Practice"; and George E. Johnson, "Changes over Time in the Union/Nonunion Wage Differential in the United States" (University of Michigan, Department of Economics, February 1981). 
Daniel Mitchell has presented evidence that union wages tend to rise more slowly than nonunion wages in periods of tight labor markets and faster in weak markets. ${ }^{45}$ It is surely true that unions with good cost-ofliving clauses did better than average in protecting real wages against surprise supply shocks. It also appears that many unions in subsequent negotiations were able to preserve these relative gains. More generally, the Mitchell findings may tentatively be expanded. Unions exert their bargaining power to claim a larger share of the bilateral surplus in career labor markets principally in ways designed to protect the real wages of their members during unfavorable demand and supply circumstances of two kinds: reduced demand for labor and a speedup in inflation not generally accompanied by increased demand for labor (such as autonomous supply shocks) ${ }^{46}$ To the extent that the hypothesis is correct, it would explain the virtually continuous widening of the gap between union and nonunion wages during the 1970 s.

The literature gives no settled answer about the extent to which an autonomous rise in union wages influences wage patterns elsewhere. But such increases did raise the supply curve in the affected industries and therefore had at least some effect on the aggregate supply curve.

In sum, having just emerged from an unprecedented boom and an upward shift in the inflation norm at the end of the 1960s, the economy was faced in the last seven years of the 1970s with three developments that pushed up its aggregate supply curve. Food and energy supply shocks required a 14 percent upward adjustment in the level of the supply curve for consumer goods. Slowed productivity growth led to a significant upward adjustment in the rate of inflation embedded in the aggregate supply curve, and a substantial exogenous upward shift occurred in the aggregate supply curve in a number of major unionized industries.

Given the unprecedented magnitude of the shocks to the aggregate supply curve, largely accommodated over the period as a whole by the growth in nominal demand, the resulting price increases were very large and undoubtedly sufficient to induce a substantial further upward shift in the norm during the 1970 s.

In addition to these "real" pressures that tended to produce upward

45. Daniel J. B. Mitchell, "Union Wage Determination: Policy Implications and Outlook," BPEA, 3:1978, pp. 537-91.

46. See James E. Annable, Jr., "Wage Norms and Interindustry Structure" (University of Maryland, Department of Economics, 1981). 
norm shifts, there may have been a problem of misperceptions. Principally because of the interaction between the way its housing component is calculated and the recent history of mortgage interest rates and home prices, the CPI in $1977-80$ rose by $5-1 / 2$ percent more than the fixed weight deflator for personal consumption expenditure. To the extent that the 1979-80 price acceleration in the CPI came as a surprise, the existence of CPI-based cost-of-living clauses in union contracts and the practice by some nonunion firms of matching relevant union wage changes got some of the "excess" CPI inflation into nominal wage increases, which in turn added their contribution to the upward pressures on the norm.

To summarize, the three sets of inflationary shocks that occurred during the past twelve to fifteen years exceeded by a huge margin any shocks in previous peacetime experience; and they came after an unprecedented period of expansion had already shifted up wage norms. Although wage and price setting in the American economy appears to have had very stable characteristics in peacetime cycles and was quite resistant to cumulative effects from demand-supply disequilibria and actual inflation experience, that stability was overwhelmed beginning in 1966 by events of historically unique magnitude.

\section{Summary of Findings}

This paper has identified a number of characteristics of the cyclical behavior of wages and prices in response to changes in aggregate demand. Some of these characteristics provide evidence that is relevant to an evaluation of competing theories about the economy's aggregate supply curve.

First, the cyclical sensitivity of the nonfarm deflator to changes in aggregate demand has been quite small in both prewar and postwar peacetime cycles. The weak responsiveness of price change to change in aggregate demand is the inverse of a large elasticity of output to aggregate demand change. The data for the nonfarm GNP suggest an observed elasticity of supply (output change relative to price change) of around 5. Such a high observed elasticity of supply cannot be reconciled with theories that explain cyclical inflation on the basis of market-clearing behavior including misperceptions and predict that adoption of a credible noninflationary macro policy would yield much larger price and much smaller output response than implied in the coefficients of mainline models. 
Second, not only was the cyclical sensitivity of the nonfarm deflator weak, it did not change between the prewar and the postwar years, at least up until the late 1960s. The cyclical sensitivity of wages did decline somewhat, but was never large to begin with. The relative constancy of price and wage flexibility over periods of quite different monetary policy regimes suggests that, contrary to rational expectations doctrine, the small size of the flexibility coefficient is itself structural, and not a spurious relation arising from the inflationary effect on price expectations of employment-supporting monetary policy in the postwar period.

Third, wholesale price flexibility did decline substantially from prewar to postwar years. Some of the decline may have been a statistical mirage, but not all of it. One hypothesis, suggested but not explored in this paper, is the spread of customer markets from the retail sphere to the wholesale sphere as a concomitant of the broader development of national markets for consumer goods.

Fourth, the lack of a systematic procyclical component to real product wages (nonfarm wages divided by the nonfarm deflator) implies that an explanation of cyclical movement in inflation cannot be explained by a combination of movements along aggregate labor supply curves and expectational or informational phenomena as posited by accelerationist theories of the business cycle.

On the one hand, the failure of real wages (measured in consumer product prices) to rise and fall procyclically strongly indicates that cyclical expansions and contractions of output do not principally represent market-clearing movements up and down the economy's labor supply curve. On the other hand, the cyclical pattern and timing of annual and monthly price movements also indicate that economic expansions are not typically driven, as accelerationist theory would seem to call for, by continuing misperceptions or information lags and by the self-defeating efforts to raise real or relative wages that lead to acceleration of inflation.

The cyclical history suggests, therefore, that over a wide range of its cyclical experience much of the fluctuation in output and employment was neither a movement along an aggregate labor supply curve nor the result of an accelerationist process of misperceptions about the relative prices (or wages) on which those curves are based.

Fifth, throughout prewar and postwar peacetime cycles, at least until 1966 , the rate of change in aggregate demand variables played an important role in determining the rate of inflation. In the prewar period the 
level of aggregate demand (relative to potential) was not a determinant of inflation; in the postwar years, however, the level of demand became a significant factor. A speed-limit model can account for the "rate-ofchange" phenomenon. Even during periods of Keynesian unemployment, expanding firms raise the level of wages relative to the prevailing norm in order to speed the flow of new recruits, and these increases are at least partially imitated by other firms.

But in the postwar period an employment-supporting policy of demand management led to expectations about demand and output that converted part of the one-time rise in the wage level-which accompanied an increase in demand relative to potential-into a continuing inflation. Such a change in behavior is consistent with a predictive or "rational" element in the formation of expectations about aggregate demand, even though economic agents do not translate that prediction about demand into money-neutral price expectations.

Sixth, the range in which the aggregate supply curve exhibits nonaccelerationist behavior is by no means unlimited. Persistent operation of the economy at low levels of unemployment or a persistent excess of actual inflation over the prevailing norm (or if one insists, relative to longerterm price expectations) will set in motion accelerationist pressures. And relatively long periods in which inflation runs below the norm can result in a downward shift in the norm, as appears to have happened in the early 1960s. The complex of forward- and backward-looking forces that influence the setting of current wages and prices shows a good bit of inertia. Because the cyclical evidence suggests that actual prices in expansions and contractions do not typically behave as if these forces changed gradually and systematically in response to moderate cyclical swings in inflation, the use of a sticky but not immutable norm to approximate their behavior seems reasonable.

\section{Concluding Comments}

The difficulty of modeling the upward norm shifts that have characterized the recent past leaves wide room for agnosticism about the chief policy issue of the time. The evidence is, I believe, fairly convincing that the norm will not be shifted significantly (or long-term price expectations reduced), even by several years of moderate negative deviations of actual 
inflation from the norm-which themselves are costly in terms of lost output and employment. Although credible evidence that demand restraint will be pursued should affect expectations about the course of nominal demand, the response of prices to such expected changes in demand will still be modest.

There is no warrant, however, for attributing norm shifts solely to actual or expected changes in demand variables. Perry and others have showed, I think convincingly, that the explosion of wages that occurred in Europe at the end of the 1960s could not be attributed to changes in demand, demand management policies, or supply shocks. ${ }^{47}$ Moreover, it is difficult to attribute the sharp rise in union wages in 1970 and 1971 in the United States solely to the standard variables.

In a climate in which actual and expected demand conditions are favorable to inflation reduction, the relatively steady trend of wages around which fluctuations in inflation take place may be influenced by a wide range of events whose effects on the norm can at least be speculated. Two major and highly visible union contracts come up for renewal in 1982 in industries that are already in trouble and whose wages are by almost any standard "out of line"-automobiles ${ }^{48}$ and trucking. As this paper is written, adamant opposition to an out-of-line wage increase for the air traffic controllers, taken at some substantial risk, appears to have been successful. Barring further government sweetening of the triggerprice mechanism, a continuing strong dollar would yield a 1983 steel bargaining climate in which the chance for wage moderation will be unusually great. At further high risk, governmental failure to exert its usual intervention in the triennial railroad bargaining impasse next year-and perhaps governmental moral support for a major revision in work rulesmight conceivably yield an important anti-inflation settlement in this industry. Should the oil glut persist, and be expected to continue, conditions for norm moderation could also be strengthened. In short, a particular concatenation of circumstances exists over the near-term future that

47. George L. Perry, "The Determinants of Wage Inflation Around the World," $B P E A, 2: 1975$, pp. 403-35; and David Soskice, "Shock Waves and Wage Explosion, 1968-1970: An Economic Interpretation," in Colin Crouch and Alessandro Pizzorno, eds., The Resurgence of Class Conflict in Western Europe Since 1968, vol. 2: Comparative Analyses (Holmes and Meier, 1978), pp. 221-46.

48. In addition, Chrysler employees' wages and fringes in 1982 will be about 20 percent below those at General Motors and Ford, and it is clearly impossible to catch up. 
offers some speculative optimism for a moderate reduction in the wage norm to counter relative pessimism about the ease with which it can be moved by actual and expected demand restraint alone.

\section{APPENDIX A}

\section{Notes on the Data}

Nominal GNP, real GNP, and the deflator for the total economy and the private nonfarm sector are based on the official U.S. Bureau of Economic Analysis series from 1909 to 1980 (for 1909-28 see table I-23 in The National Income and Product Accounts of the United States 1929-1974, GPO, 1977). Private nonfarm GNP equals total GNP minus farm and government components. It is a more inclusive measure than the oftenused "private nonfarm business" concept, and it includes GNP arising in households and institutions and the rest of the world, as well as the imputed rental services of owner-occupied dwellings. This more inclusive concept was chosen to maintain comparability in the series over time; the narrower-and possibly more useful-version is not available for years before 1929.

For years preceding 1909 the Kendrick series for current and constant dollar GNP were used. (See columns A-1 and A-7, p. 166, in U.S. Bureau of the Census, Long Term Economic Growth, 1860-1965, GPO, 1966.) A nonfarm GNP was constructed for 1900-09 by inflating the Kendrick constant dollar farm gross product (Long Term Economic Growth, column A-21) to current dollars by use of a Bureau of Agricultural Economics farm price series. (USDA Technical Bulletin 703, table 79; the index used is a Paasche price index.) There is no estimate of current dollar government product in these years; the 1900-09 estimates represent movement in nonfarm GNP. But experimentation indicated that the failure to exclude government had no significant effect on the results.

Wholesale prices are from the U.S. Bureau of Labor Statistics. The total CPI and the CPI food index measures beginning in 1913 are also from BLS data. From 1900 to 1913 the CPI is from Albert Rees' reweighting of the Douglas data (see Albert Rees, Real Wages in Manu- 
facturing, 1890-1914 (Princeton University Press, 1961), p. 74). The Kendrick-BLS series on average hours worked are from Long Term Economic Growth, 1860-1970, GPO, 1973, pp. 192-93 and from BLS. The wage series are discussed in the text.

In table 13 an estimate is presented of the effect of energy price increases on the chain-weighted price index for personal consumption expenditure (PCE). The estimate attempts to capture two effects of energy price increases: the effect on the overall index of price increases for energy products directly purchased by consumers, and the indirect effect on the index of the higher energy costs paid by industrial and commercial users and passed on to consumers in other product prices. The measure of the indirect effect was based on work by Michael McKee, formerly of the Council of Economic Advisers' staff, who calculated that nonhousehold expenditures on petroleum products in 1979 were about equal to household expenditures (0.98). It was assumed that the expenditure weights for petroleum product prices were the same for household and nonhousehold uses. Similar ratios of nonhousehold to household expenditures for natural gas and electricity were constructed, using price and quantity data for commercial and industrial consumption of these products. It was further assumed that the nonhousehold uses could be allocated to consumer goods by the following ratio-total consumer expenditure less direct outlays on energy divided by GNP less compensation of general government employees. The adjusted ratios were averaged, and the result was an overall expenditure weight for indirect energy costs, as reflected in consumer product prices. A chain-weighted index for nonhousehold energy prices was constructed, using commercial and industrial price and quantity data for natural gas and electricity and letting the PCE price index for petroleum products represent the price of nonhousehold petroleum products. Increases in the resulting price index for "indirect uses" were entered twothirds for the current and one-third for the subsequent year (to reflect an assumed lag in passing the increases through to final goods prices). The weighted contribution of indirect energy price increases to the PCE chainweighted price index was then calculated. 


\section{Is the Flexibility of the Reduced Wholesale Price Index a Statistical Mirage?}

SEVERAL REASONS exist for believing that the reduced flexibility exhibited by the wholesale price index is not wholly a statistical mirage.

First, the finished goods index shows roughly the same decline in flexibility as do the broader totals. The term "finished goods" is somewhat misleading because in earlier years the index included some intermediate goods. It also includes a few crude foods and other crude materials sold directly to final users. Nevertheless, the fact that the finished goods index exhibits the same characteristics as the other indexes must be given some weight.

Second, Cagan calculated the frequency distribution of decelerations during cycle contractions for a group of forty-four individual series beginning in $1923 .{ }^{49}$ (The change in inflation rates for each series was measured from the period preceding the peak to the trough of cycle contractions, and a cumulative frequency distribution was plotted.) With one exception (the 1948-49 contraction) the distribution shifts steadily toward smaller deceleration. ${ }^{50}$

Third, the calculation of flexibility coefficients for three individual industry groups - chemicals, metals, and household goods-from 1900 to 1966 confirms for the latter two a sharp decline in flexibility. (Cyclical price changes in the chemical industry were probably overwhelmed by the effect of rapid technical progress in the prewar period.)

This evidence is not conclusive. Even within individual subcomponents of the index, the number and importance of relatively homogenous flexprice commodities probably decreased. Nevertheless, it seems highly likely that wholesale prices became less flexible in the postwar period, not only absolutely but also in relation to changes in aggregate demand.

49. Phillip Cagan, "Changes in the Recession Behavior of Wholesale Prices."

50. This exceptional behavior of wholesale prices in the 1949 cycle is consistent with other evidence about wartime cycles discussed above. 


\section{Comments and Discussion}

William Fellner: In my comments on Charles Schultze's paper and his interpretation of the data I offer an alternative interpretation in terms of what I consider the valid core of rationality hypotheses in the theory of expectations. As I see it, this valid core overlaps significantly with what in earlier writings I called the hypothesis of the credibility effect. That hypothesis places emphasis on the effect of a consistent and credible policy posture on market expectations and thus on cost and price trends.

Schultze's analysis of cost and price trends, on the other hand, gives great significance to the inertia of an inflation norm originating in the past experience of market participants. This inflation norm has characteristics of a rule of thumb or convention. Aside from factors that may be regarded as exogenous, the price level is viewed in the paper as dependent on the size of this inflation norm and on the level of "real" activity. The influence of the level of activity can be seen in the fact that keeping real activity supernormal by the standards of an economy raises the price level, though it causes no acceleration as long as the inert inflation norm remains unchanged; and keeping the level of activity subnormal reduces the price level, though it causes no deceleration as long as the inert inflation norm remains unchanged.

In arguing that until the experience of the 1960s the inflation norm remained low and did not change much, the paper focuses on thirty-six years that, however, do not make up a continuum. These years start with a pre-World War I phase of the gold-standard era-the period from 1900 to 1913 - then continue with six years of the 1920 s, and finally include seventeen years of the period following World War II, namely the years from the late 1940s to the mid-1960s. According to the argument, the exceptionally long expansion of the 1960s, during which demand policy 
kept activity levels well above normal for an extended period, led to inflation far exceeding the norm originating in the preceding periods. Inert though the norm is, it has not proved to be so inert that it is unaffected by the cumulation of such a large discrepancy. That is, the events of the second half of the 1960s resulted in a significant increase in the inflation norm, which now shows the inertia it has always shown but at a significantly higher level.

If one is determined to limit oneself to the years of the analysis in the paper, a limitation I do not suggest, it may be difficult to distinguish support for Schultze's inert inflation norm from support for the hypothesis I favor, which stresses the effect of a credible policy posture on expectations. Yet even if one limited the analysis to the years in the paper, I would still suggest that, other things equal, the hypothesis of intelligent foresight of credible policies deserves to be given preference over a hypothesis postulating a mechanistic adherence to rules of thumb. Even with a focus on the years to which Schultze's analysis primarily relates, it needs to be kept in mind that in the period from 1900 to the outbreak of World War I, markets must have been well aware of the likelihood that the new gold discoveries of the turn of the century would tilt the price trend mildly upward, following a period of a downward-tilted price trend that ended in 1896. And from the post-Korean period until the mid-1960s-another major part of Schultze's sample- the markets had good reason to expect a tough demand policy guided mainly by the objective of price stability with a small margin for upward movement. For periods with these characteristics the effect of a credible policy posture may be hard to distinguish from what Schultze describes as the effect of a small and inert inflation norm. However, one of these two hypotheses has at least the advantage of crediting market participants with some degree of intelligence and perceptiveness instead of regarding them as following blind rules of thumb, and crediting economists with the ability to figure these out.

In the years following the mid-1960s the markets must have realized that the monetary authorities became increasingly willing to accommodate steepening rates of inflation that were considered necessary to achieve short-term employment policy goals, even if on various occasions full accommodation had to be temporarily discontinued to prevent the process from getting out of hand at an early stage. This was indeed a new attitude of the authorities toward the problems they were facing, and the change of attitude was a very damaging one. In Schultze's presentation an increase 
in conventional inflation norms occurred in that phase, but in this case, too, it seems much more convincing to me to assume that after a while the markets proved perceptive enough to realize a change in the policy posture and that expectations were strongly influenced by this realization.

So far these comments may give the impression that the entire debate is concerned with the difference between two ways of telling essentially the same story. But the difference clearly ceases to be that, or merely that, once one asks why it is necessary to limit the period analyzed in Schultze's paper to specific years if support is to be provided for a moderate but inert conventional inflation "norm" until the mid-1960s. The specific years included in Schultze's sample are mainly the years in which, given U.S. monetary institutions and the policy posture of the monetary authorities, the price trend has shown a mild upward trend. Whereas the period discussed in the paper includes also six years of the 1920s for which the price trend was practically horizontal, these have a small weight in the sample as a whole.

But what if the pre-1965 subperiods are included in which expectations were not conditioned by a close approximation to price stability with a small margin for upward movement? Could it be argued also that for subperiods with those characteristics, which were not included in the Schultze sample, the effect of policy postures on market expectations can alternatively be described as Schultze's inert norms or rules of thumb? Could it be argued also for those subperiods that inert norms change only when long-lasting overutilization or underutilization creates a major discrepancy between the norm and the actual inflation rate (by analogy to the 1960s)? I do not see how it could be.

Schultze states that, in contrast to the experience of the 1960s, the inflations brought about by the two world wars did not break the earlier convention of the small and inert inflation norm because these inflationary times were regarded as atypical events. I think he should have added the Korean inflationary explosion as a third illustration under the same heading, but regardless of whether two or three instances are included, the essential point is that at those times the authorities succeeded in convincing the public that in postwar periods they would not continue to accommodate inflation, and therefore no extended period of underutilization was needed to prevent a large inflation norm from becoming incorporated into postwar market practices. These events do fall in place for the hypothesis suggesting the effect of credible policy postures on ex- 
pectations but not for the hypothesis of the inert inflation norm. And what if the analysis had been made to cover the period from 1879 to 1896 , which preceded the gold discoveries of the end of the century, and during which the gold standard that prevailed became associated with a mildly downward-tilted price trend? In that period of gold scarcity the markets had good reason to associate such a price trend with the gold standard, but they can hardly be assumed to have carried over conventional pricetrend norms from the preceding era. During that preceding era the Californian and Australian discoveries of the mid-century had made gold unusually abundant for a while.

And what if the analysis included the years preceding the resumption of gold convertibility in 1879 ? In anticipation of that resumption at $\$ 20.67$ an ounce the markets had in those years very good reason to expect a much steeper downward trend of prices than that which continued subsequently, and this steeper downward trend did actually develop and proved compatible with a substantial upward trend in output. That clearly happened in the anticipation of a credible change in policy posture and cannot conceivably be interpreted as the application of any rule of thumb originating in past price experience.

One may take the position that going back too far in history makes comparisons irrelevant; however, once one goes back to 1900 the argument against going back another quarter of a century is not particularly convincing. If one decides to focus on the post-Korean era, Schultze's analysis is apt to direct attention to a proposition that lacks the historical dimensions of the one I have considered above. This is Schultze's proposition that even when anti-inflationary policies were reasonably successful during the early part of the post-Korean era-say, from the end of the Korean War to about 1965-the moderation of nominal demand expansion during the recessions showed up in little moderation of the price trend (or of the wage and price trend). This proposition receives a good deal of attention in Schultze's paper, but to me it seems to stress a numerical relation of doubtful importance.

What matters is that, in the early phase of the post-Korean era when the anti-inflationary policy posture was credible, recessions that were associated with just enough demand moderation to play it safe in the direction of policy restraint turned slightly and temporarily upward deviating wage and price trends back to what the markets believed the authorities were 
determined to achieve. The demand restraint applied at those times accomplished this result with little delay. This is what matters in any attempt to judge the record of a credible anti-inflationary policy. The fact that even in the 1950s and the early 1960s demand restraint did not reduce the steepness of the wage or price trend by the number of percentage points now needed to restore a practically noninflationary economy is not a point deserving emphasis. The validity of this statement goes without saying. A reduction in the rate of wage and price increase by the number of percentage points now needed could have been achieved by demand restraint in the 1950s and early 1960s only if the posture of the authorities had been interpreted as one aiming for a steeply deflationary price trend. There obviously was no reason to interpret the posture as such.

As may be clear from these comments, I believe that a consistent antiinflationary policy would succeed in breaking what Schultze refers to as an increased inflation norm. Such a policy would not accomplish this overnight, but it would succeed after an adjustment period whose duration depends on the time it takes to establish credibility and to overcome the carry-over effect of past cost commitments. A detailed discussion of the implications of the inevitability of an adjustment period is not within the scope of my comments. But I want to stress the difference between recognizing the inevitability of such an adjustment period and what to me seems an essential but unconvincing suggestion of the Schultze paper. This is the suggestion that the very steep present inflation allowances in cost setting will not give way before a high degree of underutilization has lasted long enough to bring about a substantial discrepancy between the actual inflation experience and these inflation allowances.

Robert J. Gordon: It is fitting that this paper is presented on the fiftieth anniversary of Britain's departure from the gold standard (September 21, 1931), an event that helped plunge the United States into the worst phase of its 1929-33 economic contraction. The puzzling nature of the price and wage adjustment process during the years between the two world wars, which contributed to the length and severity of the Great Depression, is further elucidated in Charles Schultze's ambitious and stimulating paper. I welcome Schultze as he joins the small group of investigators 
who have sailed out of the safe harbor of postwar U.S. data on a voyage to explore the relatively uncharted prewar waters. ${ }^{1}$

The leading questions in historical investigations of U.S. aggregate price behavior pertain to the responsiveness of price changes to changes in nominal GNP (or money) and to the level of utilization or unemployment, the role of lagged price changes and the validity of the accelerationist hypothesis, and the nature and timing of changes in behavior. Findings on all three questions matter for current policy debates, since the balance between demand responsiveness and inertia in the behavior of aggregate price changes determines the output loss associated with a sustained effort to decelerate the growth of nominal demand. A judgment on the probability of future shifts of parameters in response to policy changes requires an evaluation of the only available evidence on the issue-the nature of such parameter shifts in the past.

In several papers (cited in Schultze's first footnote) I have been working to develop an answer to these questions. I would like to summarize my approach and results to provide a context for my subsequent evaluation of Schultze's paper. In the same notation that Schultze has adopted, with uppercase letters denoting logs of levels, and lowercase letters denoting rates of change, I start by assuming that the rate of change of the GNP deflator $\left(p_{t}\right)$ depends on its own lagged values, on the level and rate of change of the ratio of real GNP to natural (or potential) real GNP $\left(\hat{Q}_{t}=Q_{t}-Q_{t}^{*}\right)$, and on a vector of supply shifts $\left(z_{t}\right)$ :

$$
p_{t}=a(L) p_{t-1}+b_{0} \hat{Q}_{t}+b_{1} \Delta \hat{Q}_{t}+b_{2} z_{t}+e_{t}
$$

where $a(L)$ is a polynomial in the lag operator and $e_{t}$ is an error term. Defining adjusted nominal GNP growth as the excess of the growth rate of nominal GNP over that of natural real GNP $\left(\hat{y}_{t}=y_{t}-q_{t}^{*}\right)$, the use of an identity $\left(\hat{Q}_{t} \equiv \hat{Q}_{t-1}+\hat{y}_{t}-p_{t}\right)$ allows the derivation of a relation be-

1. In addition to Schultze's footnote citations to work by Cagan, Sachs, and me, additional recent contributions include the papers and comments contained in Karl Brunner, ed., The Great Depression Revisited (Boston: Martinus Nijhoff, 1981 ); R. A. Gordon, "Wages, Prices, and Unemployment, 1900-1970," Industrial Relations, vol. 14 (October 1975), pp. 273-301; Allan Meltzer, "Anticipated Inflation and Unanticipated Price Change," Journal of Money, Credit and Banking, vol. 8 (May 1978), pp. 182-205; and Christopher A. Sims, "Comparison of Interwar and Postwar Business Cycles: Monetarism Reconsidered," American Economic Review, vol. 70 (May 1980, Papers and Proceedings, 1979), pp. 250-57. 
tween price change, adjusted nominal GNP change, and the lagged level of the output ratio:

$$
p_{t}=\frac{1}{1+b_{0}+b_{1}}\left[a(L) p_{t-1}+\left(b_{0}+b_{1}\right) \hat{y}_{t}+b_{0} \hat{Q}_{t-1}+b_{2} z_{t}+e_{t}\right]
$$

In this framework the significance of the estimated coefficient on the lagged output ratio indicates the presence of an output "level effect," while the difference between the coefficient on adjusted nominal GNP growth and the lagged output ratio indicates the relative size of the "rateof-change effect." If the coefficients on lagged price change and on adjusted nominal GNP change sum to unity, then the accelerationist hypothesis is validated in the sense that a positive output ratio $\left(\hat{Q}_{t-1}>0\right)$ or an adverse supply shift $\left(z_{t}>0\right)$ causes an acceleration of the inflation rate relative to its past value. ${ }^{2}$

Questions may be raised about the appearance of nominal GNP change in equation 2 above, an equation explaining price change. Nominal GNP change is indeed an endogenous variable, although no more so than the current unemployment rate that has traditionally been used in Phillips curve studies. The advantage of using equation 2 for estimation instead of equation 1 becomes clear when considering a period like 191522 , when prices responded promptly and completely to changes in nominal GNP, with little residual effect on real GNP. In a world of fast price responsiveness to serially correlated nominal GNP movements, an investigator who forces all of the price adjustment to be explained by real variables and lagged price change, as in 1 , will find the results plagued by positive serial correlation and an upward bias in the coefficient on lagged price change. Another alternative to 2 , which involves replacing nominal GNP change with the change in a monetary aggregate, has the quite different disadvantage that the resulting coefficient on money will mix aggregate demand and aggregate supply effects; that is, it reflects the combined influence of the response of velocity to monetary changes and the response of prices to nominal GNP changes. Finally, the most obvious source of bias in the coefficient on nominal GNP change, stemming from

2. Schultze's equation 1a is identical to my equation 2 , with the omission of the lagged output ratio $\left(\hat{Q}_{t-1}\right)$, if one associates his $P_{A}$ with my $b_{2} z_{t}$, and his $P_{N}$ with my $a(L) p_{t-1}$. 
the simultaneous increase in prices and nominal GNP that would occur when supply shocks are accompanied by an accommodating monetary policy, can be mitigated by careful attention to the specification of the supply shift variables $\left(z_{t}\right)$.

The empirical results in table 1 below provide four alternative estimates of equation 2 for the eighty-eight years extending between 1892 and 1980 . The format of table 1 represents my first comment on Schultze's paper, since my methodology that estimates a single equation characterizing the entire sample period differs radically from Schultze's methodology that divides history into segments-peacetime, wartime, Great Depression, and post-1966 - with no tests of statistical significance provided to support the hypothesis of radical shifts in structure between segments. Most other previous investigations of historical data have also divided the sample period, most typically by omitting entirely the years of the Great Depression and World War II. My approach does not rule out changes in structure but rather attempts to quantify parameter shifts in a way that provides a measure of the statistical significance of each shift.

The results in table 1 are arranged from worst-fitting on the left to best-fitting on the right. The first column displays a naive Phillips curve, in which price change is allowed to depend only on a constant and on the lagged values of the output ratio and of the dependent variable. The second column adds nominal GNP change, with the implied result that almost half of nominal GNP change is absorbed by price change in the current year. In both of these columns the level effect, the traditional Phillips curve hypothesis that price change depends on the level of utilization, is insignificant.

The third column adds the supply shift variables, of which five are dummy variables to capture the impact of five different episodes of government intervention in the price-setting process, and the sixth is the annual change in the relative price of food and energy. The dummy variables are not of the usual 0,1 form. My own previous research on the Nixon controls and the National Recovery Act finds that both programs not only shifted the price level during their official period of impact but caused a shift in the opposite direction after their termination. All dummy variables in table 1 are defined to sum to 1.0 during the period of a program's impact, and to -1.0 during the period after its termination, thus constraining the impact and rebound effects to have exactly the same absolute value. The resulting coefficients on the dummy variables indicate the cumulative displacement of the price level during the period of the 
Table 1. Equations Explaining the Annual Percentage Change in the GNP Deflator, 1892-1980a

\begin{tabular}{|c|c|c|c|c|}
\hline $\begin{array}{l}\text { Independent variable, constant, } \\
\text { and summary statistic }\end{array}$ & $\begin{array}{l}\text { Naive } \\
\text { Phillips } \\
\text { curve }\end{array}$ & $\begin{array}{c}\hat{y} \\
\text { added }\end{array}$ & $\begin{array}{c}\text { Supply } \\
\text { shifts } \\
\text { added }\end{array}$ & $\begin{array}{l}\text { Parameter } \\
\text { shifts }\end{array}$ \\
\hline \multicolumn{5}{|l|}{ Adjusted nominal GNP $\left(\hat{y}_{t}\right)$} \\
\hline Entire period & $\ldots$ & 0.44 & 0.46 & 0.33 \\
\hline Extra effect, 1915-22 & $\ldots$ & $\ldots$ & $\ldots$ & 0.54 \\
\hline Extra effect, $1942-49$ & $\ldots$ & $\ldots$ & $\ldots$ & 0.19 \\
\hline Lagged adjusted nominal GNP $\left(\hat{\mathrm{y}}_{t-1}\right)$ & $\ldots$ & $\ldots$ & $\ldots$ & $0.10^{\mathrm{b}}$ \\
\hline \multicolumn{5}{|l|}{ Lagged real GNP ratio $\left(\hat{Q}_{t-1}\right)$} \\
\hline Entire period & $0.01^{\mathrm{c}}$ & $0.07 \mathrm{e}$ & $0.06^{\mathrm{b}}$ & 0.18 \\
\hline Extra effect, 1929-41 & ... & $\ldots$ & $\ldots$ & -0.17 \\
\hline \multicolumn{5}{|l|}{ Lagged price change $\left(\tilde{p_{t-1}}\right)^{\mathrm{d}}$} \\
\hline Entire period & 0.50 & $0.20^{\mathrm{b}}$ & 0.27 & $0.05^{\mathrm{c}}$ \\
\hline Extra effect, $1950-80$ & $\ldots$ & $\ldots$ & $\ldots$ & 0.41 \\
\hline \multicolumn{5}{|l|}{ Supply shiftse } \\
\hline World War I controls, 1915-22 & $\ldots$ & $\ldots$ & -5.46 & -8.82 \\
\hline National Recovery Act, 1933-36 & $\ldots$ & $\ldots$ & 8.23 & 7.21 \\
\hline World War II controls, 1943-47 & $\ldots$ & $\ldots$ & -17.80 & -19.00 \\
\hline Korean War controls, 1950-52 & $\ldots$ & $\ldots$ & $-0.25^{\mathrm{c}}$ & $-2.54^{b}$ \\
\hline Nixon controls, $1972-75$ & $\ldots$ & $\ldots$ & -5.00 & -4.76 \\
\hline Relative price of food and energy, $1947-80^{\mathrm{f}}$ & .. & $\ldots$ & 1.03 & $0.54 \mathrm{~g}$ \\
\hline Constant term & 1.46 & 1.29 & 0.97 & $0.61^{\mathrm{b}}$ \\
\hline \multicolumn{5}{|l|}{ Summary statistic } \\
\hline $\mathbf{R}^{2}$ & 0.25 & 0.64 & 0.79 & 0.92 \\
\hline Standard error of estimate & 4.71 & 3.29 & 2.55 & 1.63 \\
\hline
\end{tabular}

Source: A data appendix is available on request from the author.

a. All coefficients are statistically significant at the 1 percent level unless otherwise indicated. For 18901954 the level of natural real GNP, $Q^{*}$, used to create the $\hat{y}_{t}$ and $\hat{Q}_{t}$ variables is computed by the method described in Robert J. Gordon, Macroeconomics, 2d ed. (Little, Brown and Co., 1981), appendix C, pp. 22-23. For 1954-80 the level of $Q^{*}$ is taken from Robert J. Gordon, "Inflation, Flexible Exchange Rates, and the Natural Rate of Unemployment," Working Paper 708 (National Bureau of Economic Research, July 1981), appendix B.

b. Significant at the 5 percent level.

c. Not significant.

d. In equations containing the supply-shif $t$ variables, the lagged price change is computed by netting out the influence of the special factors. Thus if $D_{i}$ is the level of dummy variable $i$ and $d_{i}$ is its coefficient, then net lagged price change is calculated as

$$
\tilde{p_{t-1}}=p_{t-1}-\sum_{i=1}^{5} d_{i} D_{i, t-1}-d_{0} p_{t-1}^{F},
$$

where $d_{0}$ is the coefficient on the relative food-energy price variable, $p_{t}^{F E}$.

e. All dummy variables are defined to sum to unity during the period when a program of government intervention is in effect and to -1 af ter its termination. The National Recovery Act, World War II, and Nixon dummy variables are defined exactly as in Gordon, "A Consistent Characterization of a NearCentury of Price Behavior," American Economic Review, vol. 70 (May 1980, Papers and Proceedings, 1979), p. 246, note 10. The World War I and Korean dummy variables are new. The variables are as follows.

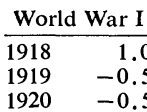

$$
\begin{gathered}
\begin{array}{c}
\text { National } \\
\text { Recovery Act }
\end{array} \\
\hline
\end{gathered}
$$

\begin{tabular}{|c|c|}
\hline Kor & War \\
\hline 1950 & -0.5 \\
\hline 1951 & -0.5 \\
\hline 1952 & 1.0 \\
\hline
\end{tabular}

\begin{tabular}{rr}
\hline 1933 & 0.4 \\
1934 & 0.6 \\
1935 & -0.4
\end{tabular}

\begin{tabular}{lr}
\multicolumn{2}{c}{ World War II } \\
\hline 1943 & 0.5 \\
1944 & 0.4 \\
1945 & 0.1 \\
1946 & -0.6 \\
1947 & -0.4
\end{tabular}

\begin{tabular}{lr}
\multicolumn{2}{c}{ Nixon controls } \\
\hline 1972 & 0.5 \\
1973 & 0.5 \\
1974 & -0.3 \\
1975 & -0.7
\end{tabular}

f. The variable used to represent changes in the relative price of food and energy is the difference between the annual rates of change of the deflators for, respectively, personal consumption expenditure and personal consumption expenditure net of expenditure on food and energy. This variable is available only for $1947-80$ and is set equal to zero before 1947 .

g. Significant at the 10 percent level. 
program's impact. ${ }^{3}$ An advantage of this method is that, because all dummy variables sum to zero, collectively they do not explain any of the elevenfold increase in the GNP deflator that occurred between 1892 and 1980.

The coefficients on the supply shift variables in the third column are significant (except for the Korean War dummy) and of plausible magnitudes. In light of the tightness of the World War II price controls and the 50 percent rate of inflation that occurred in the third quarter of 1946 after their termination, the estimated cumulative impact of -18 percent seems conservative. The impact of World War I controls was less than half as large, as was the National Recovery Act in the opposite direction. ${ }^{4}$ The impact of the Nixon controls was smaller still, but still significant.

In addition to its interesting and novel findings regarding the behavior of wage rates, the consumer price index and the wholesale price index, on which I will not comment directly, Schultze's paper makes four main points about the behavior of the implicit GNP deflator. First, with the exception of a greater degree of flexibility in wartime, the flexibility coefficient, $\Delta p / \Delta \hat{y}$, remained remarkably steady for the private nonfarm sector at 15 to 20 percent throughout the period between 1900 and 1966 . Second, the level effect of the output ratio is purely a postwar phenomenon. Third, coefficients on lagged price change do not support the accelerationist hypothesis before 1967. Finally, the upsurge of inflation after 1966 cannot be described as a continuous response to quantifiable variables, and instead must be discussed in the language of discrete "norm shifts."

Because most of these results involve presumed shifts in parameter values over time, I have investigated whether there were significant shifts in the coefficients on the four economic variables $\left(\hat{y}_{t}, \hat{y}_{t-1}, \hat{Q}_{t-1}\right.$, and $\left.p_{t-1}\right)$ for the following subperiods-1892-1903, 1904-14, 1915-22, 1929-41, 1942-49, 1950-53, 1954-66, and 1967-80. I also tested for a shift in the constant term for $1967-80$. Of the thirty-three possible parameter shifts

3. The dummy variables are defined in note e to table 1 . The odd timing of the Korean War variable reflects my verdict that the Korean War controls did no more than capture the unwinding of the speculative commodity boom of 1950-51.

4. For a discussion of World War I controls see F. W. Taussig, "Price-Fixing as Seen by a Price-Fixer," Quarterly Journal of Economics, vol. 33 (February 1919), pp. 205-41. 
thus tested, only four were significant, and these are displayed in the fourth column. ${ }^{5}$

The results partially support and partially contradict those of Schultze. First, our shared verdict that the flexibility coefficient, $\Delta p / \Delta \hat{y}$, was stable remains intact (with a large upward parameter shift during the World War I period and a smaller upward shift during World War II). My 33 percent estimate of the full-period effect for total GNP is larger than the 22 percent one obtains from averaging his prewar and postwar effects for total GNP. Supporting Schultze's verdict that level effects were absent in the Great Depression and the entire impact of demand worked through rate-of-change effects, the "extra effect, 1929-41" entry, row 8 of table 1 , shows that the coefficient on the level effect was completely canceled out during 1929-41. But the form of this result provides the first refutation of Schultze's results, for he argues that the level effect is purely a postwar phenomenon, whereas my statistical search supports the verdict that the level effect was about the same in 1892-1929 as after World War II. There is no explicit contradiction here because Schultze never actually estimates a prewar equation that excludes 1929-41. Next, the coefficient on row 11, "extra effect, 1950-80," supports a positive inertia effect beginning in 1950 .

Taken together, the results in the fourth column of table 1 contradict two of Schultze's main points. The first point is that, far from denying the accelerationist hypothesis for 1950-66, the coefficients indicate a response of price change to a permanent increase of nominal GNP growth for the entire 1950-80 period of almost unity. ${ }^{6}$ (The relevant sum of coefficients adds that in the "entire period" row for current adjusted nominal GNP growth, that for "lagged adjusted nominal GNP," and the two coefficients for lagged price change-that is, $0.33+0.10+0.05+0.41=$ 0.89.) My search pins down the date of the shift in the role of price inertia at 1950 , not 1942,1954 , or 1967 . This provides support for the hypothesis that the advent of the three-year overlapping staggered U.S. wage

5. The fourth column also includes a significant impact of the lagged value of nominal GNP change.

6. Although a sum of coefficients of unity is consistent with the accelerationist hypothesis, a sum of coefficients below unity does not necessarily conflict with that hypothesis, an important point originally made in Thomas J. Sargent, "A Note on the Accelerationist Controversy," Journal of Money, Credit and Banking, vol. 3 (August 1971), pp. 721-25. 
contract in 1948 explains the greater degree of wage and price inertia in the postwar United States than in other countries.

Schultze's second point, that the $1967-80$ period cannot be explained without invoking the concept of the norm shift, raises a methodological issue. Schultze's methodological hypothesis, that it is impossible to provide a convincing econometric explanation of post-1966 price changes, is implicit but never proved, since no failed equations are provided. I have tried to find statistically significant shifts for the 1967-80 subperiod in the equation reported in the fourth column of table 1 . I have tested for shifts in every variable, including further lags of the dependent variable $\left(p_{t-2}\right.$, $\left.\ldots, p_{t-5}\right)$ and have found nothing. The test that seems closest to what Schultze has in mind, a shift in the constant term for 1967-80, yields a coefficient of 0.8 with a $t$-ratio of 0.9 . Just as the response of the inflation rate to the acceleration of money and nominal GNP growth between 1966 and 1970 can be adequately captured by conventional time-series econometric techniques, so the hypothetical adjustment of inflation to a monetary deceleration can be captured by the same methods. The amazing implication of my own research, as summarized in table 1 , is that the structure of price behavior has changed so little, not so much, and that there is thus scant historical evidence to support the vague claims of the Lucas critique of econometric policy evaluation. I believe that the good news thus far in 1981 on wage and price behavior is a prelude to more of the same, and that what went up will come down, in much the same way and at more or less the same pace. ${ }^{7}$

Charles Schultze: The contrast between my findings and those of Robert Gordon are starker than Gordon himself suggests. Because the coefficient on the aggregate demand variable in his equations is relatively stable, he interprets his equations as implying, like my own analysis, an unchanged basic structure of price behavior between prewar and postwar years, with somewhat greater inertia in the latter period due to the introduction of three-year staggered wage contracts. But one must take all parts of the equation into account to address this question, particularly the implicit

7. An explicit factor that may have increased the responsiveness of prices to monetary policy, the advent of flexible exchange rates, is not incorporated in table 1 but is treated in detail in Gordon, "Inflation, Flexible Exchange Rates, and the Natural Rate of Unemployment," Working Paper 708 (National Bureau of Economic Research, July 1981), appendix B. 
and explicit coefficients on current and lagged price change. When one does this, Gordon's equations for the postwar period imply an accelerationist economy in which output is ultimately neutral to changes in nominal demand and in which four-fifths of the long-run price adjustment takes place within three years. By contrast, his prewar results describe an economy that was far from being accelerationist or money-neutral.

Gordon's coefficient on aggregate demand is higher than mine for two reasons: first, Gordon uses the total GNP deflator rather than my lessresponsive private nonfarm deflator. Second, I subtract the norm rate of inflation from both the change in the deflator and the change in nominal GNP, which necessarily leads to a lower coefficient.

Finally, although Gordon offers strictures against segmentation of the analysis into various periods, his own equations show the need for some kind of segmentation. Gordon has four periods with different behavioral characteristics, which he captures by his "extra effects" coefficients. The major difference between us is that he does not break the postwar period into two parts, divided after the mid-1960s.

I disagree with William Fellner's argument that the stability of my flexibility coefficient could be predicted on rational expectations grounds because the experience with monetary policy or monetary growth was roughly similar during the peacetime cycles I analyzed. It was not. The standard deviations of annual changes in prices around norm inflation rates and the money supply (M2) around its trend rates of growth were one and a half to two times as large in the prewar peacetime cycles as in the post-Korean War period (through 1966). According to rational expectations theory, this should have led to a substantially changed expectational framework in the latter period and hence to a much different observed response of inflation to changes in aggregate demand.

\section{General Discussion}

Joseph Pechman asked Charles Schultze and the two formal discussants to describe the likely duration and cost of a macroeconomic policy that would lead to price stability. Based on his own work, Robert Gordon said that, starting from an initial inflation rate of 10 percent, inflation could be reduced to 5 percent over a five-year period if the monetary authorities were willing to slow the growth of nominal GNP by 1 percent 
a year. The real cost of such a program would be a gap between actual and potential GNP of 4 percent by the fifth year, and a cumulative loss of 25 to 30 percent of one year's real GNP over the decade that would elapse before output and unemployment returned to normal. Schultze had no quantitative evidence about the necessary duration of a stabilization program because his model does not yield predictions about the future of inflation norms. However, he felt that a program depending on aggregate demand reductions would take longer to succeed than Gordon's quantitative results suggested. William Fellner stated that estimates based on historical experience during periods of an accommodative basic policy posture will overstate the costs of disinflation. He believed stability could be attained during the course of a single business cycle, depending on the length of time it takes for authorities to establish the credibility of their program and also depending on the carry-over effects of presently existing long-term contracts. Although the required recession did not necessarily have to be severe, the recovery would at least have to be slow.

Benjamin Friedman observed that any attempt to make disinflation a credible policy regardless of its cost would require too much time to be accomplished by a single Congress or administration. For the policy to be credible, the public would have to believe the administration would win reelection despite the costs its policy would impose on the voters. Edmund Phelps was skeptical that the stabilization policy described by Gordon would actually be pursued. He pointed out that although the authorities may control some version of the money supply, $M$, they hardly control $\mathrm{M} \times \mathrm{V}$, money multiplied by its velocity, or nominal GNP. Even assuming $\mathrm{M} \times \mathrm{V}$ could be reduced in line with Gordon's nominal GNP targets, the authorities might not want to accept its possible side effects such as bank failures.

In the same vein, Donald Hester questioned whether the government should focus its authority on establishing credibility for its price stabilization program as Fellner and others had urged. Hester pointed out that there are many areas in which the credibility of government is important, such as defense policy, foreign relations, and guarantees against the collapse of financial institutions. If these conflict with economic policy, attempts to establish credibility about price expectations should not take precedence over them.

A spirited discussion centered around Schultze's definition and use of 
inflation norms. Alan Blinder believed that the norm approach implied inflationary expectations moved in a steplike manner, which he found implausible. He reasoned that when one aggregates over the beliefs of many firms and consumers, even if those individual beliefs move discontinuously, the sum of expectations will move in a smooth way. Charles Holt agreed that discontinuous jumps are implausible, but he sympathized with Schultze's aim of modeling expectations as ordinarily stable even when observed inflation is fluctuating. He suggested that expectations might be nonlinear, rising rapidly once inflation reaches a threshold value. William Nordhaus objected that he did not understand the theory behind threshold effects and agreed with Blinder that expectations ought to change continuously. He also objected to Robert Gordon's excessive use of dummy variables to deal with developments that did not fit the basic model. Schultze responded to the critics of his view by arguing that there is more going on in the formation of inflationary expectations than can be accounted for by simple adaptive expectations. But he agreed that he does not have a satisfactory way to predict when the norm will change.

Lawrence Summers pointed out that the movements in long-term interest rates over the late 1960s and 1970s provide some indirect support for discontinuously changing inflation norms. Bond rates rose to a new plateau at the end of the 1960 s, from which they varied only a little despite large variations in actual inflation, and then moved to a new plateau again at the end of 1970s. Martin Baily pointed out that the norm view has an optimistic as well as a pessimistic policy interpretation. The current administration could take hope from Schultze's view that the norm could be discontinuously reduced, although his analysis did not describe what effect particular policies would have on it. Norm changes have typically followed actual inflation developments, although they might also be responsive to new policy regimes. Robin Marris observed that evidence of something like a norm shift in the late 1960s was apparent in inflation relations for most industrial countries. In estimates of conventional Phillips curve relations, these show up either as discontinuous shifts in the constant terms or in enlarged coefficients on lagged inflation.

Jeffrey Sachs observed that Schultze's own results for wages and wholesale prices show they are now less responsive to demand fluctuations than they were earlier. Therefore he questioned Schultze's overall conclusion 
that the cyclical responsiveness of inflation has changed little over long periods and different policy regimes. Schultze responded that, first, the most relevant results are those for final prices, so the wage and wholesale price results are less important; and second, wages never were very flexible so the decline in the postwar period represents little change. Sachs noted that whether the change in the flexibility coefficient for wages is important depends on what question is asked. When a small flexibility coefficient on wages becomes even smaller, it means that the large output cost of slowing wage inflation has become even larger. 